NCCN

Non-Small Cell

Lung Cancer,

Version 5.2017

\section{Clinical Practice Guidelines in Oncology}

David S. Ettinger, MD; Douglas E. Wood, MD, FRCSEd;

Dara L. Aisner, MD, PhD; Wallace Akerley, MD;

Jessica Bauman, MD; Lucian R. Chirieac, MD;

Thomas A. D'Amico, MD; Malcolm M. DeCamp, MD;

Thomas J. Dilling, MD, MS; Michael Dobelbower, MD, PhD;

Robert C. Doebele, MD, PhD; Ramaswamy Govindan, MD;

Matthew A. Gubens, MD, MS; Mark Hennon, MD;

Leora Horn, MD, MSc, FRCPC; Ritsuko Komaki, MD;
Rudy P. Lackner, MD; Michael Lanuti, MD; Ticiana A. Leal, MD;

Leah J. Leisch, MD; Rogerio Lilenbaum, MD; Jules Lin, MD;

Billy W. Loo Jr, MD, PhD; Renato Martins, MD, MPH;

Gregory A. Otterson, MD; Karen Reckamp, MD, MS;

Gregory J. Riely, MD, PhD; Steven E. Schild, MD;

Theresa A. Shapiro, MD, PhD; James Stevenson, MD;

Scott J. Swanson, MD; Kurt Tauer, MD; Stephen C. Yang, MD;

Kristina Gregory, RN, MSN, OCN; and Miranda Hughes, PhD

\section{Overview}

This selection from the NCCN Clinical Practice Guidelines in Oncology (NCCN Guidelines) for Non-Small Cell Lung Cancer (NSCLC) focuses on targeted therapies and immunotherapies for metastatic NSCLC, because new recommendations were added for the 2017 updates. For example, new

\begin{abstract}
This selection from the NCCN Guidelines for Non-Small Cell Lung Cancer (NSCLC) focuses on targeted therapies and immunotherapies for metastatic NSCLC, because therapeutic recommendations are rapidly changing for metastatic disease. For example, new recommendations were added for atezolizumab, ceritinib, osimertinib, and pembrolizumab for the 2017 updates.
\end{abstract}

J Natl Compr Canc Netw 2017;15(4):504-535

\section{NCCN Categories of Evidence and Consensus}

Category 1: Based upon high-level evidence, there is uniform NCCN consensus that the intervention is appropriate.

Category 2A: Based upon lower-level evidence, there is uniform NCCN consensus that the intervention is appropriate.

Category 2B: Based upon lower-level evidence, there is $\mathrm{NCCN}$ consensus that the intervention is appropriate.

Category 3: Based upon any level of evidence, there is major NCCN disagreement that the intervention is appropriate.

\section{All recommendations are category $2 \mathrm{~A}$ unless otherwise noted.}

Clinical trials: NCCN believes that the best management for any cancer patient is in a clinical trial. Participation in clinical trials is especially encouraged.

\section{Please Note}

The NCCN Clinical Practice Guidelines in Oncology $\left(\mathrm{NCCN}\right.$ Guidelines $\left.{ }^{\circledR}\right)$ are a statement of consensus of the authors regarding their views of currently accepted approaches to treatment. Any clinician seeking to apply or consult the NCCN Guidelines ${ }^{\circledR}$ is expected to use independent medical judgment in the context of individual clinical circumstances to determine any patient's care or treatment. The National Comprehensive Cancer Network ${ }^{\circledR}\left(\mathrm{NCCN}^{\circledR}\right)$ makes no representation or warranties of any kind regarding their content, use, or application and disclaims any responsibility for their applications or use in any way.

(C) National Comprehensive Cancer Network, Inc. 2017, All rights reserved. The NCCN Guidelines and the illustrations herein may not be reproduced in any form without the express written permission of NCCN.

\section{Disclosures for the Non-Small Cell Lung Cancer Panel}

At the beginning of each NCCN Guidelines panel meeting, panel members review all potential conflicts of interest. NCCN, in keeping with its commitment to public transparency, publishes these disclosures for panel members, staff, and NCCN itself.

Individual disclosures for the NCCN Non-Small Cell Lung Cancer Panel members can be found on page 535. (The most recent version of these guidelines and accompanying disclosures are available on the NCCN Web site at NCCN.org.)

These guidelines are also available on the Internet. For the latest update, visit NCCN.org. 
recommendations were added for atezolizumab, ceritinib, osimertinib, and pembrolizumab.

The complete version of the NCCN Guidelines for NSCLC, available at NCCN.org, addresses all aspects of management for NSCLC. Additional sections in the complete version of the NCCN Guidelines include "Principles of Pathologic Review," "Principles of Surgical Therapy," "Principles of Radiation Therapy," "Chemotherapy Regimens for Neoadjuvant and Adjuvant Therapy," "Systemic Therapy for Advanced or Metastatic Disease," "Cancer Survivorship Care," "Emerging Agents for Patients with Genetic Alterations," and "Staging."

The NCCN Guidelines for NSCLC were first published in 1996, ${ }^{1}$ and are updated at least once a year by the NCCN panel; there were 5 updates from January 2016 to January 2017. By definition, the NCCN Guidelines cannot incorporate all possible clinical variations and are not intended to replace good clinical judgment or individualization of treatments. A brief introduction to NSCLC is provided in the following paragraphs.

Lung cancer is the leading cause of cancer death in the United States. ${ }^{2}$ In 2017, an estimated 222,500 new cases $(116,990$ in men and 105,510 in women) of lung and bronchial cancer will be diagnosed, and 155,870 deaths $(84,590$ in men and 71,280 in women) are estimated to occur because of the disease. ${ }^{3}$ Only $17.7 \%$ of all patients with lung cancer are alive $\geq 5$ years after diagnosis. ${ }^{4}$ However, much progress has been made recently for lung cancer such as screening, minimally invasive techniques for diagnosis and treatment, and advances in radiation therapy (RT), including stereotactic ablative RT (SABR), targeted

Text cont. on page 515 .

\section{NCCN Non-Small Cell Lung Cancer Panel \\ Members}

*David S. Ettinger, MD/Chair

The Sidney Kimmel Comprehensive Cancer Center at Johns Hopkins

*Douglas E. Wood, MD, FRCSEd/Vice Chairq

Fred Hutchinson Cancer Research Center/

Seattle Cancer Care Alliance

Dara L. Aisner, MD, PhD $\neq$

University of Colorado Cancer Center

Wallace Akerley, MD +

Huntsman Cancer Institute at the University of Utah

Jessica Bauman, MD $\ddagger$

Fox Chase Cancer Center

Lucian R. Chirieac, MD $\neq$

Dana-Farber/Brigham and Women's Cancer Center

Thomas A. D'Amico, MD

Duke Cancer Institute

Malcolm M. DeCamp, MDף

Robert H. Lurie Comprehensive Cancer Center of

Northwestern University

Thomas J. Dilling, MD, MS§

Moffitt Cancer Center

Michael Dobelbower, MD, PhD§

University of Alabama at Birmingham

Comprehensive Cancer Center

Robert C. Doebele, MD, PhDt

University of Colorado Cancer Center

Ramaswamy Govindan, MDt

Siteman Cancer Center at Barnes-Jewish Hospital and

Washington University School of Medicine

Matthew A. Gubens, MD, MSt

UCSF Helen Diller Family Comprehensive Cancer Center

Mark Hennon, MDף

Roswell Park Cancer Institute

Leora Horn, MD, MSc, FRCPC $\dagger$

Vanderbilt-Ingram Cancer Center

Ritsuko Komaki, MD§

The University of Texas MD Anderson Cancer Center

Rudy P. Lackner, MDף

Fred \& Pamela Buffett Cancer Center

Michael Lanuti, MD I

Massachusetts General Hospital Cancer Center

Ticiana A. Leal, MD†

University of Wisconsin Carbone Cancer Center
Leah J. Leisch, MDP

University of Alabama at Birmingham

Comprehensive Cancer Center

Rogerio Lilenbaum, MD†

Yale Cancer Center/Smilow Cancer Hospital

Jules Lin, MDף

University of Michigan Comprehensive Cancer Center

Billy W. Loo Jr, MD, PhD§

Stanford Cancer Institute

Renato Martins, MD, MPH

Fred Hutchinson Cancer Research Center/

Seattle Cancer Care Alliance

Gregory A. Otterson, MD†

The Ohio State University Comprehensive Cancer Center James Cancer Hospital and Solove Research Institute

Karen Reckamp, MD, MSt‡

City of Hope Comprehensive Cancer Center

Gregory J. Riely, MD, PhDtP

Memorial Sloan Kettering Cancer Center

Steven E. Schild, MD§

Mayo Clinic Cancer Center

Theresa A. Shapiro, MD, PhD¥

The Sidney Kimmel Comprehensive Cancer Center at Johns Hopkins

James Stevenson, MD†

Case Comprehensive Cancer Center/

University Hospitals Seidman Cancer Center and

Cleveland Clinic Taussig Cancer Institute

Scott J. Swanson, MDף

Dana-Farber/Brigham and Women's Cancer Center

Kurt Tauer, MD†

St. Jude Children's Research Hospital/

University of Tennessee Health Science Center

Stephen C. Yang, MDI

The Sidney Kimmel Comprehensive Cancer Center at Johns Hopkins

NCCN Staff: Kristina Gregory, RN, MSN, OCN, and

Miranda Hughes, PhD

KEY:

*Discussion Section Writing Committee

Specialties: †Medical Oncology; П Surgery/Surgical Oncology; §Ra-

diation Oncology/Radiotherapy; $\neq$ Pathology; $¥$ Hematology/Hema tology Oncology; фDiagnostic/Interventional Radiology; ¥Patient

Advocate; PInternal Medicine 
CLINICAL PRESENTATION

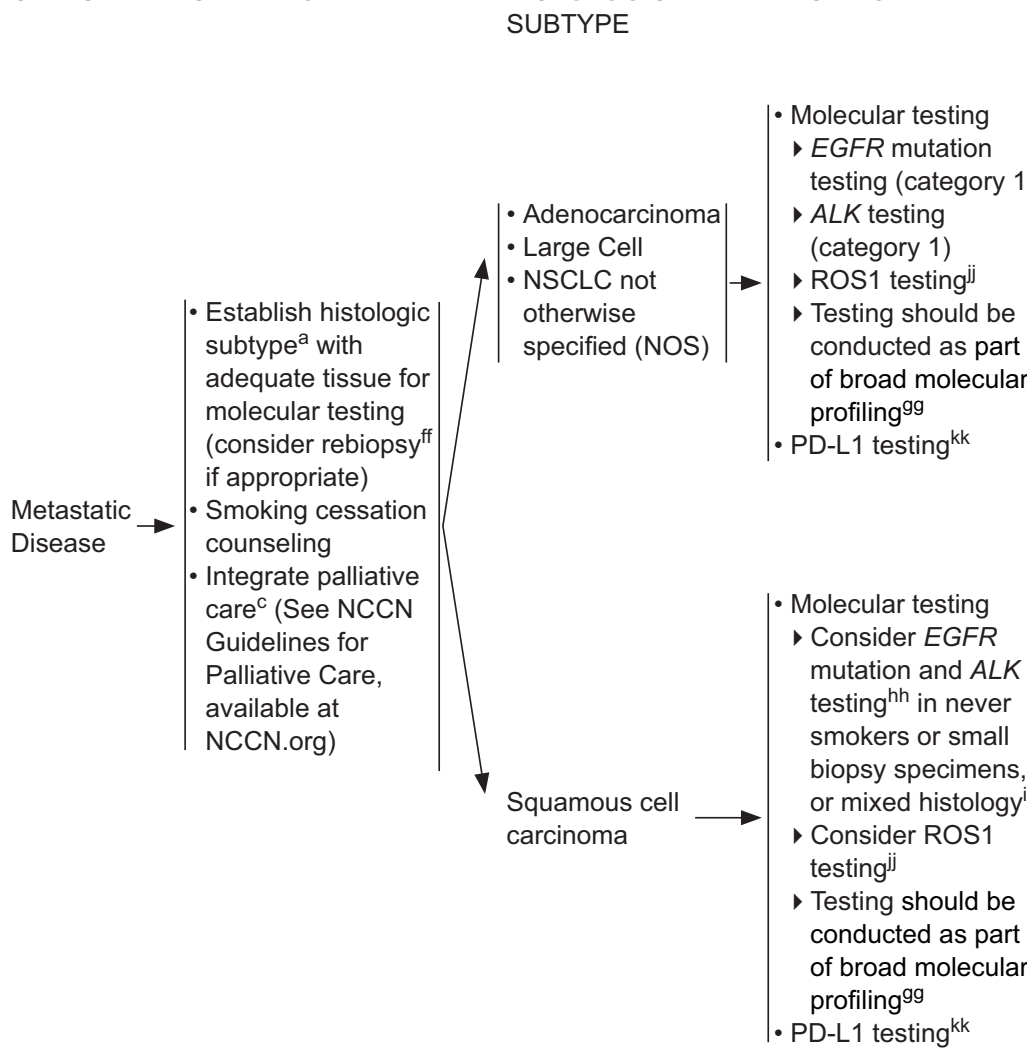

\section{HISTOLOGIC TESTINGa} SUBTYPE

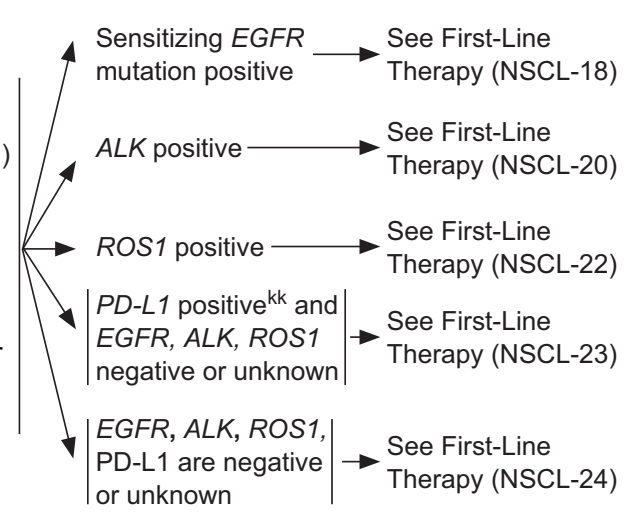

\section{TESTING RESULTS}

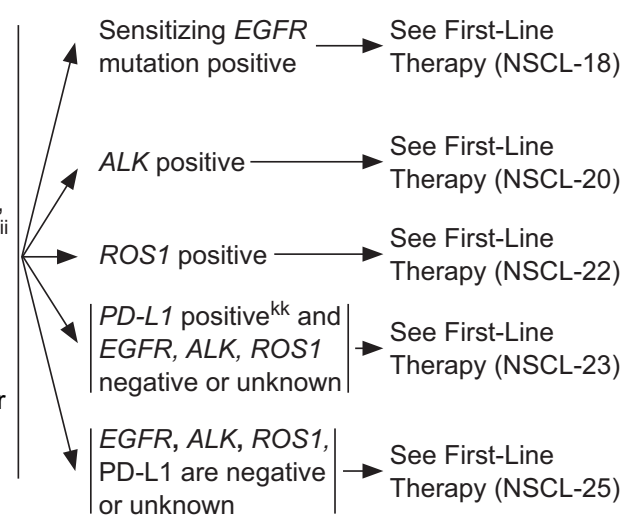

aSee Principles of Pathologic Review (NSCL-A, available online, in these guidelines, at NCCN.org).

'Temel JS, Greer JA, Muzikansky A, et al. Early palliative care for patients with metastatic non-small-cell lung cancer. N Engl J Med 2010;363:733-742.

ff If repeat biopsy is not feasible, plasma biopsy should be considered.

ggThe NCCN NSCLC Panel strongly advises broader molecular profiling with the goal of identifying rare driver mutations for which effective drugs may already be available, or to appropriately counsel patients regarding the availability of clinical trials. Broad molecular profiling is a key component of the improvement of care of patients with NSCLC. See Emerging Targeted Agents for Patients With Genetic Alterations (NSCL-H, available online, in these guidelines, at NCCN.org). hh In patients with squamous cell carcinoma, the observed incidence of EGFR mutations is $2.7 \%$ with a confidence that the true incidence of mutations is less than $3.6 \%$. This frequency of EGFR mutations does not justify routine testing of all tumor specimens. Forbes SA, Bharma $\mathrm{G}$, Bamford S, et al. The catalogue of somatic mutations in cancer (COSMIS). Curr Protoc Hum Genet 2008;chapter 10:unit 10.11.

iiPaik PK, Varghese AM, Sima CS, et al. Response to erlotinib in patients with EGFR mutant advanced non-small cell lung cancers with a squamous or squamous-like component. Mol Cancer Ther 2012;11:2535-2540.

jjShaw AT, Ou SH, Bang YJ, et al. Crizotinib in ROS1-rearranged non-small cell lung cancer. N Engl J Med 2014;371:1963-1971.

kkPD-L1 expression levels of $\geq 50 \%$ are a positive test result for first-line pembrolizumab therapy.

NSCL-17 


\section{Non-Small Cell Lung Cancer, Version 5.2017}

\section{SENSITIZING EGFR MUTATION POSITIVEa}

\section{FIRST-LINE THERAPY}

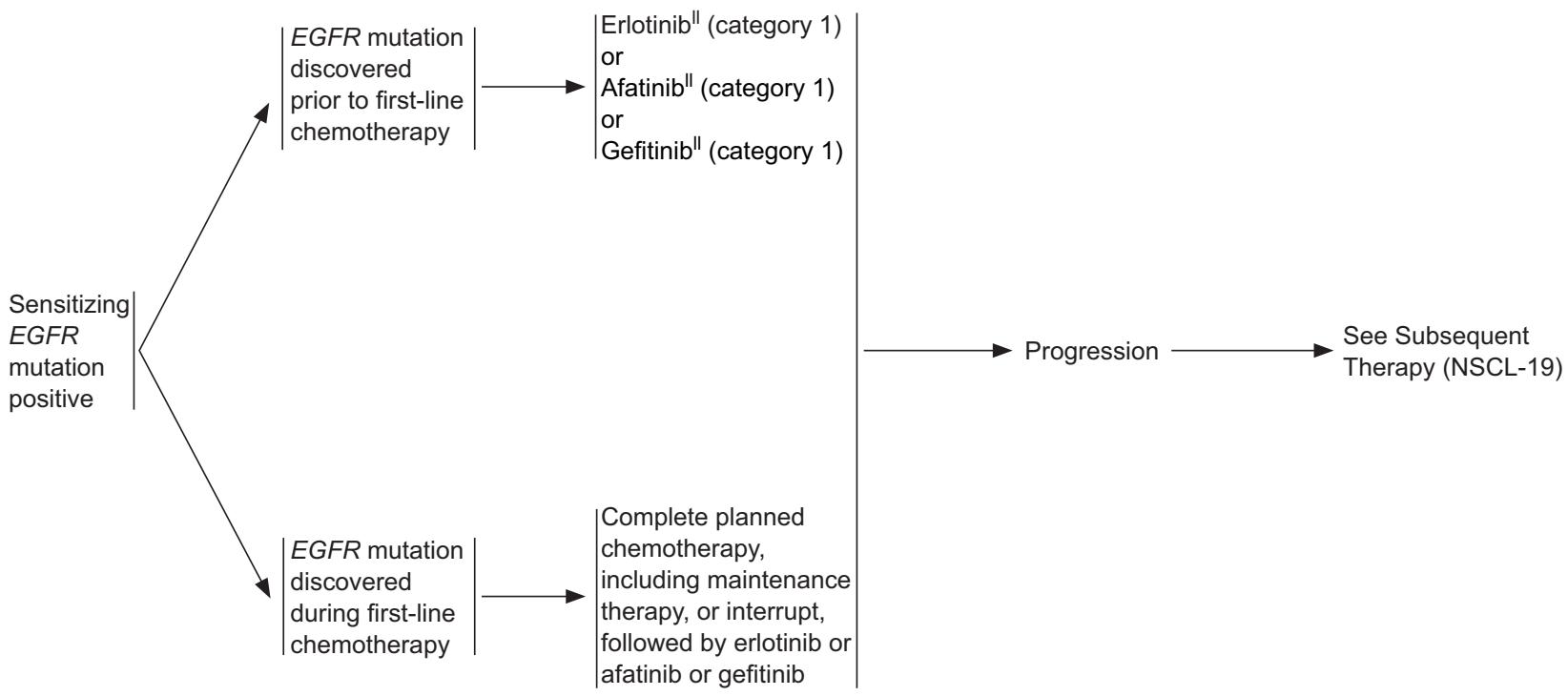




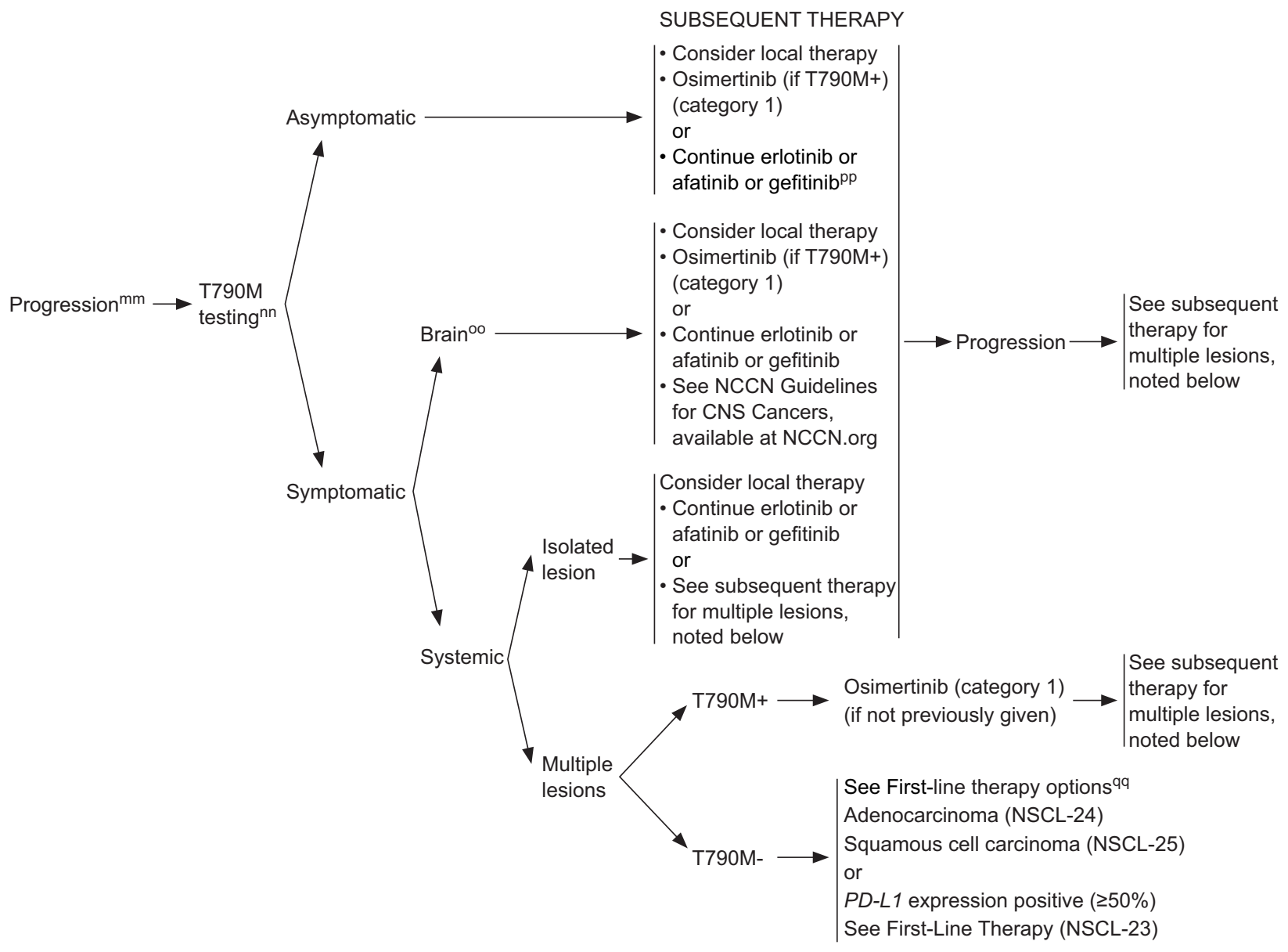

aSee Principles of Pathologic Review (NSCL-A, available online, in these guidelines, at NCCN.org).

mm Beware of flare phenomenon in subset of patients who discontinue EGFR TKI. If disease flare occurs, restart EGFR TKI.

$\mathrm{nn}$ If tissue biopsy is not feasible, plasma biopsy should be considered. Consider reflex to tissue-based testing, if plasma test is negative for the T790M mutation.

${ }^{\circ}$ Consider pulse erlotinib for carcinomatosis meningitis.

ppFor rapid radiologic progression or threatened organ function, alternate therapy should be instituted.

qqAfatinib + cetuximab may be considered in patients with disease progression on EGFR TKI therapy. 


\section{Non-Small Cell Lung Cancer, Version 5.2017}

\section{ALK REARRANGEMENT POSITIVEa}

\section{FIRST-LINE THERAPY}

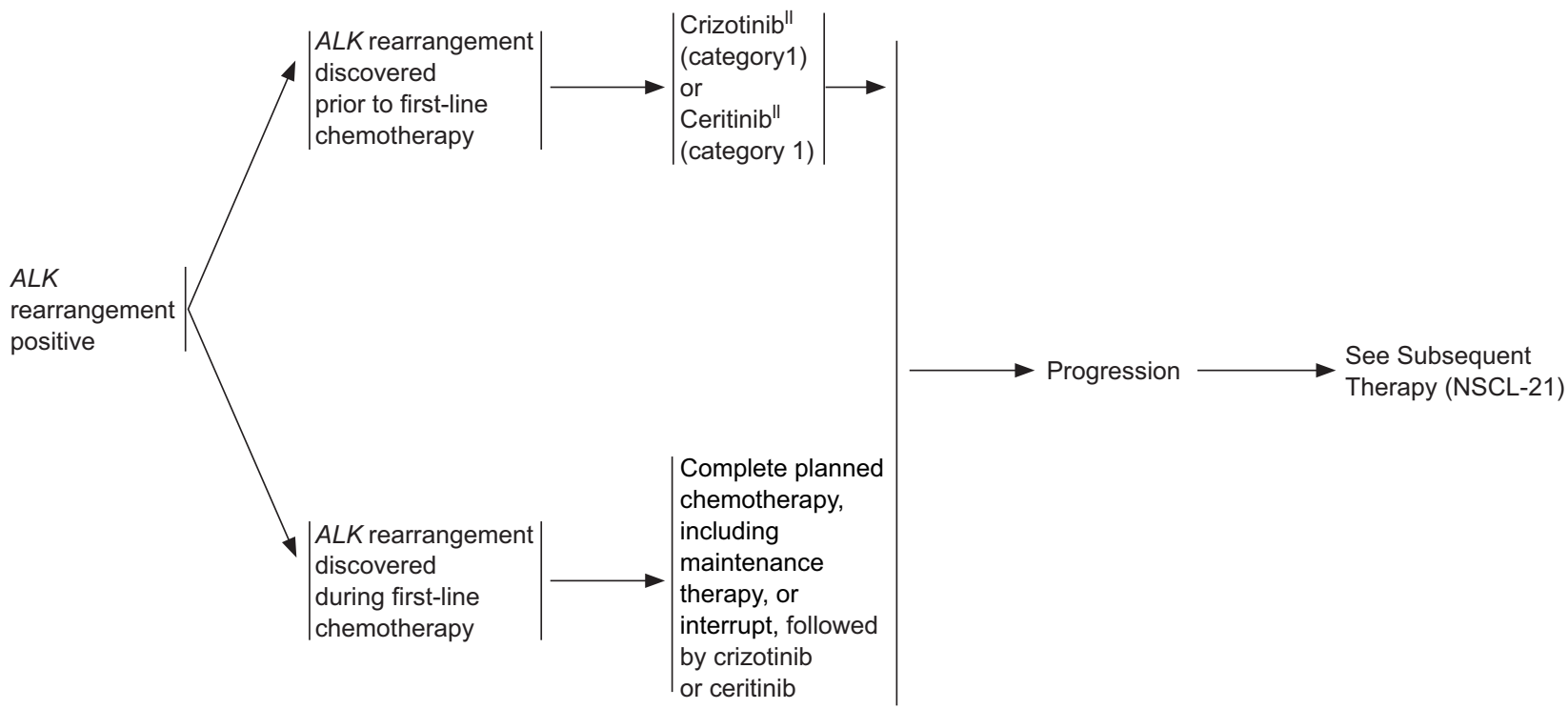




\section{SUBSEQUENT THERAPY}

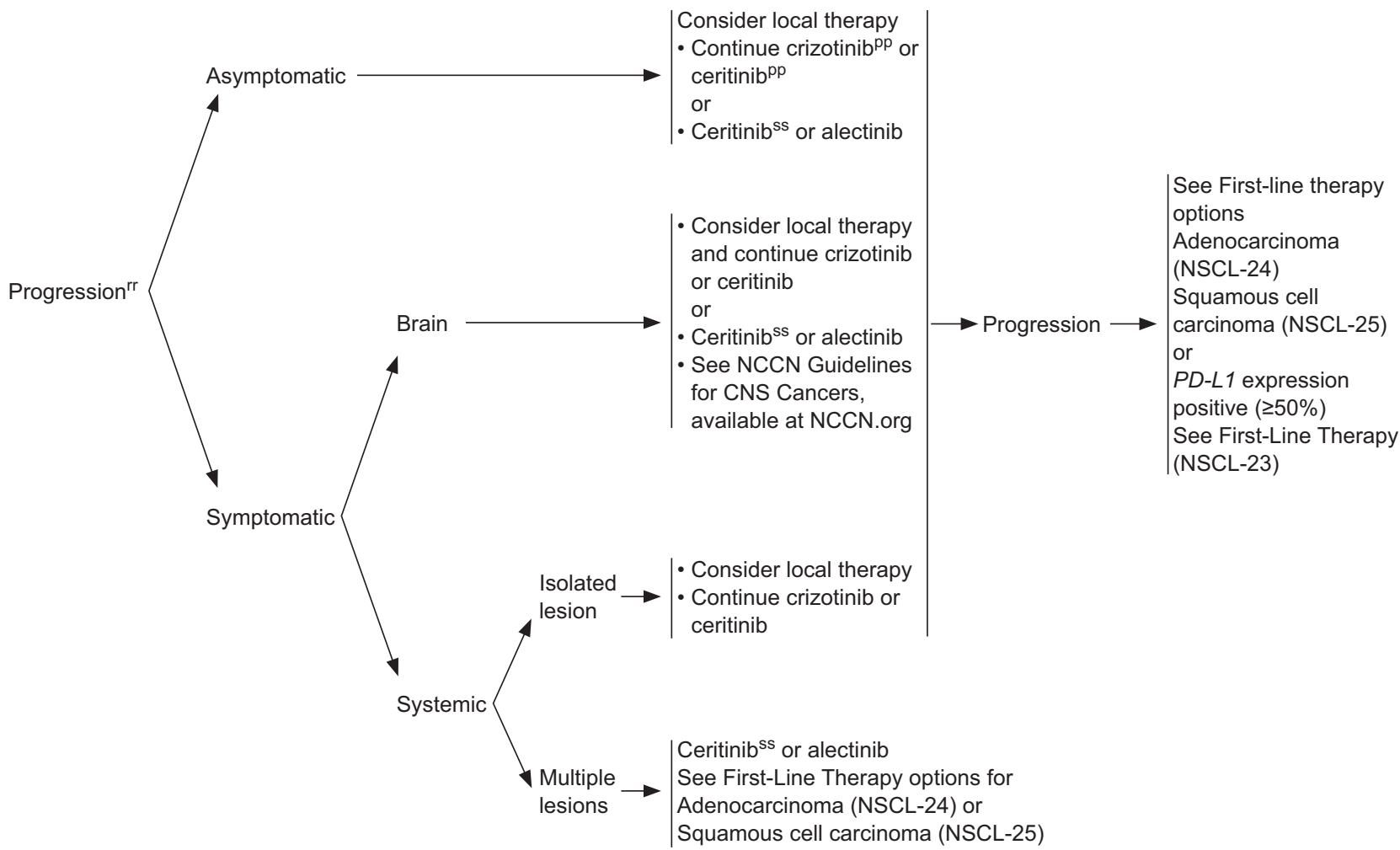




\section{Non-Small Cell Lung Cancer, Version 5.2017}

ROS1 REARRANGEMENT POSITIVE

FIRST-LINE THERAPY

SUBSEQUENT THERAPY

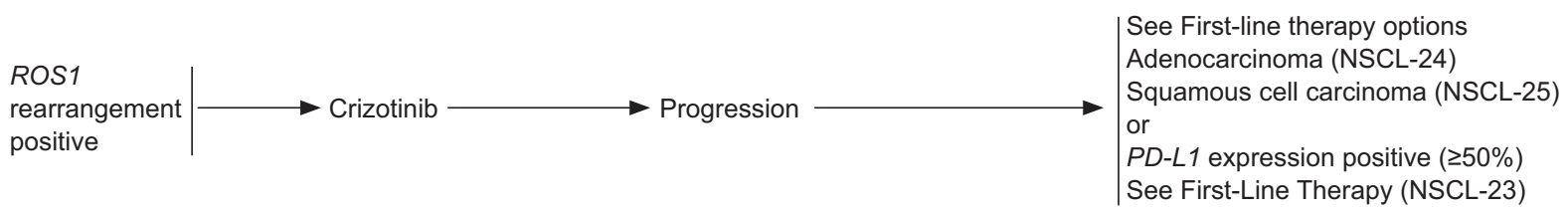

asee Principles of Pathologic Review (NSCL-A, available online, in these guidelines, at NCCN.org).

NSCL-22

Version 5.2017, 03-16-17 @2017 National Comprehensive Cancer Network, Inc. All rights reserved. The NCCN Guidelines ${ }^{\circledR}$ and this illustration may not be reproduced in any form without the express written permission of NCCN ${ }^{\circledR}$.

(C) JNCCN_Journal of the National Comprehensive Cancer Network | Volume 15 Number 4 | April 2017 
PD-L1 EXPRESSION POSITIVE ${ }^{a}$

$P D-L 1$ expression positive $(\geq 50 \%)$ and EGFR, ALK $R O S 1$ negative or unknown
Pembrolizumab ${ }^{\text {tt }}$

(category 1)
See First-Line Therapy options for Adenocarcinoma (NSCL-24) or Squamous cell carcinoma (NSCL-25)

aSee Principles of Pathologic Review (NSCL-A, available online, in these guidelines, at NCCN.org).

ttReck M, Rodríguez-Abreu D, Robinson AG, et al. Pembrolizumab versus chemotherapy for PD-L1-positive non-small-cell lung cancer. N Engl J Med 2016;375:1823-1833.

NSCL-23 


\section{Non-Small Cell Lung Cancer, Version 5.2017}

\section{ADENOCARCINOMA, LARGE CELL, NSCLC NOS}

FIRST-LINE THERAPY

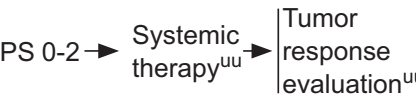

Best supportive care See NCCN Guidelines for Palliative Care, available at NCCN.org
SUBSEQUENT THERAPYUU

Systemic immune checkpoint inhibitors (preferred) Nivolumab (category 1$)^{\mathrm{vv}}$ or pembrolizumab (category 1$)^{\mathrm{ss}, \mathrm{xx}}$ or atezolizumab (category 1$)^{\mathrm{vv}}$ or

Other systemic therapy:ss

Docetaxel or pemetrexed or gemcitabine or

ramucirumab + docetaxel
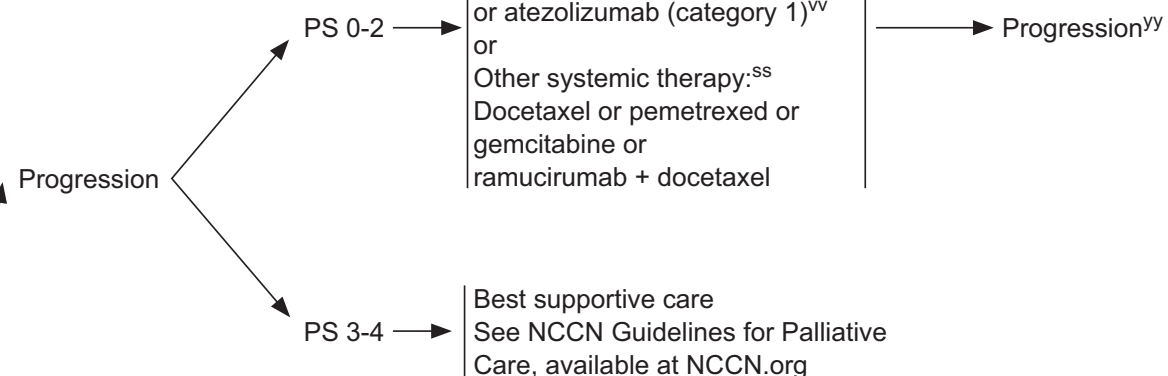

Best supportive care

See NCCN Guidelines for Palliative

Care, available at NCCN.org

Progression $\rightarrow$ See Subsequent therapy, above

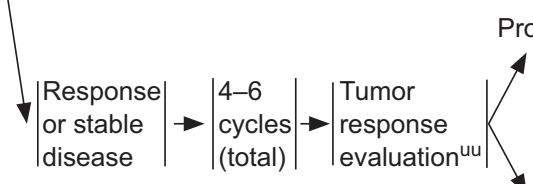

4 Continuation maintenance ${ }^{\mathrm{uu}}$

- Bevacizumab (category 1)

- Pemetrexed (category 1)

- Bevacizumab +

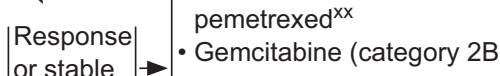
or stable
disease $\rightarrow \rightarrow$ or

Switch maintenance uu

(category 2B)

- Pemetrexed

or

Close observation
Progression, see

Subsequent therapy, above

\section{ss If not previously given}

uuSee Systemic Therapy for Advanced or Metastatic Disease (NSCL-F, available online, in these guidelines, at NCCN.org).

vvlf pembrolizumab not previously given.

wwPembrolizumab is approved for patients with NSCLC tumors with PD-L1 expression levels $\geq 1 \%$, as determined by an FDA-approved test.

$\mathrm{xx}_{\mathrm{If}}$ bevacizumab was used with a first-line pemetrexed/platinum chemotherapy regimen.

yy If not already given, options for PS 0-2 include (nivolumab, pembrolizumab, or atezolizumab), docetaxel (category 2B), pemetrexed (category 2B), gemcitabine (category $2 \mathrm{~B}$ ), or ramucirumab + docetaxel (category $2 \mathrm{~B}$ ); options for PS $3-4$ include best supportive care. Options for further progression are best supportive care or clinical trial.

NSCL-24

Version 5.2017, 03-16-17 @2017 National Comprehensive Cancer Network, Inc. All rights reserved. The NCCN Guidelines ${ }^{\circledR}$ and this illustration may not be reproduced in any form without the express written permission of NCCN ${ }^{\circledR}$. 


\section{SQUAMOUS CELL CARCINOMA}

FIRST-LINE THERAPY

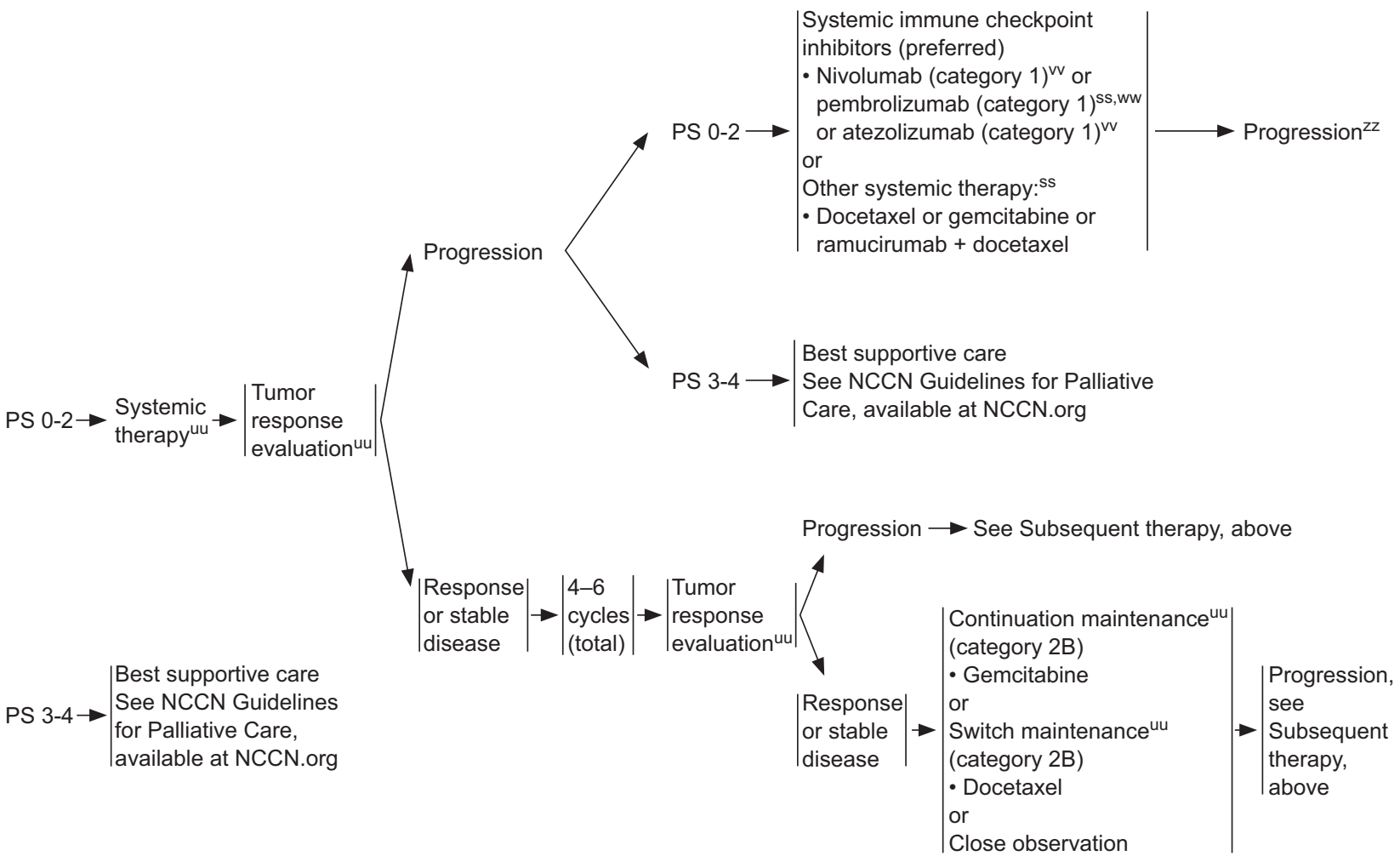

ss If not previously given.

uuSee Systemic Therapy for Advanced or Metastatic Disease (NSCL-F, available online, in these guidelines, at NCCN.org).

vvlf pembrolizumab not previously given.

wwPembrolizumab is approved for patients with NSCLC tumors with PD-L1 expression levels $\geq 1 \%$, as determined by an FDA-approved test.

zzIf not already given, options for PS 0-2 include (nivolumab, pembrolizumab, or atezolizumab), docetaxel (category 2B), gemcitabine (category 2B), or ramucirumab + docetaxel (category 2B); options for PS 3-4 include best supportive care. Options for further progression are best supportive care or clinical trial.

NSCL-25

Clinical trials: NCCN believes that the best management of any cancer patient is in a clinical trial. Participation in clinical trials is especially encouraged. All recommendations are category $2 \mathrm{~A}$ unless otherwise indicated.

(C) JNCCN-Journal of the National Comprehensive Cancer Network | Volume 15 Number 4 | April 2017 
therapies, and immunotherapies. ${ }^{5-8}$ Common symptoms of lung cancer include cough, dyspnea, weight loss, and chest pain; patients with symptoms are more likely to have chronic obstructive pulmonary disease. ${ }^{9}$

The WHO divides lung cancer into 2 major classes based on its biology, therapy, and prognosis: NSCLC and small cell lung cancer (SCLC) (see the NCCN Guidelines for SCLC, available at NCCN.org). ${ }^{10,11}$ NSCLC accounts for $>80 \%$ of all lung cancer cases, and it includes 2 major types: nonsquamous, including adenocarcinoma, large-cell carcinoma, and other cell types; and squamous cell (epidermoid) carcinoma. ${ }^{4}$ Adenocarcinoma is the most common type of lung cancer seen in the United States and is also the most frequently occurring histology in nonsmokers.

Currently, most patients with NSCLC are diagnosed with advanced cancer, although increasing use of lung cancer screening may alter the most typical stage at diagnosis. Symptoms of metastatic cancer include weight loss, bone pain, headaches, anemia, and paraneoplastic syndromes. ${ }^{12}$ The preliminary diagnosis of metastatic disease is based on symptoms, signs, and laboratory tests ${ }^{12}$; it is aided by imaging (eg, PET/CT scan, brain MRI). ${ }^{13,14} \mathrm{~Pa}$ tients with widespread metastatic disease (stage IV) are usually candidates for systemic therapy (consisting of chemotherapy, targeted therapy, or immunotherapy, depending on performance status [PS] and results from biomarker testing), clinical trials, and/ or palliative treatment.

\section{Predictive and Prognostic Biomarkers}

Several biomarkers have emerged as predictive and prognostic markers for NSCLC. A predictive biomarker is indicative of therapeutic efficacy, because there is an interaction between the biomarker and therapy on patient outcome. A prognostic biomarker is indicative of patient survival independent of the treatment received, because the biomarker is an indicator of the innate tumor aggressiveness (see “KRAS Mutations," page 518).

Predictive biomarkers include the ALK fusion oncogene (fusion between ALK and other genes [eg, echinoderm microtubule-associated protein-like 4]), ROS1 gene rearrangements, and sensitizing EGFR mutations (see "Principles of Pathologic Review" in the complete version of these guidelines, available at
NCCN.org [NSCL-A]). Emerging biomarkers include HER2 (also known as ERBB2) and BRAF V600E mutations, RET gene rearrangements, and high-level MET amplifications or MET exon 14 skipping mutations (see "Emerging Targeted Agents for Patients with Genetic Alterations" in the complete version of these guidelines, at NCCN.org [NSCL-H]).

\section{EGFR Mutations}

In patients with NSCLC, the most commonly found EGFR mutations are deletions in exon 19 (exon 19del [with conserved deletion of the LREA sequence] in $45 \%$ of patients with EGFR mutations) and a mutation in exon 21 (L858R in 40\%). Both mutations result in activation of the tyrosine kinase domain, and both are associated with sensitivity to the small molecule tyrosine kinase inhibitors (TKIs), such as erlotinib, gefitinib, and afatinib (see "EGFR TKIs," page 519). ${ }^{15}$ Thus, these mutations are referred to as sensitizing EGFR mutations. Previously, erlotinib was commonly used in the United States in patients with sensitizing EGFR mutations because of restrictions on the use of gefitinib. However, gefitinib was recently reapproved by the FDA based on a phase IV study and is now available in the United States. ${ }^{16}$ Afatinib is an oral TKI that inhibits the entire ErbB/HER family of receptors, including EGFR and HER2. ${ }^{17,18}$ The FDA has approved afatinib for first-line treatment of patients with metastatic nonsquamous NSCLC who have sensitizing EGFR mutations. ${ }^{19,20}$

These sensitizing EGFR mutations are found in approximately $10 \%$ of Caucasian patients with NSCLC and up to $50 \%$ of Asian patients. ${ }^{21}$ Other drug-sensitive mutations include point mutations at exon 21 (L861Q) and exon 18 (G719X). ${ }^{22}$ Primary resistance to TKI therapy is associated with KRAS mutations and ALK or ROS1 gene rearrangements. Patients with exon 20 insertion mutations are also resistant to TKIs. ${ }^{23-26}$ EGFR T790M is a mutation associated with acquired resistance to EGFR TKI therapy and has been reported in approximately $60 \%$ of patients with disease progression after initial response to erlotinib, gefitinib, or afatinib. ${ }^{27-34}$ Most patients with sensitizing EGFR mutations become resistant to erlotinib, gefitinib, or afatinib after approximately 9 to 13 months of EGFR TKI therapy. ${ }^{29,35-37}$ However, studies suggest T790M may also occur in patients who have not previously received EGFR TKI therapy, although this is a rare event. ${ }^{38}$ 
Osimertinib is recommended (category 1 ) as secondline and beyond (subsequent) therapy for patients with EGFR T790M whose disease has progressed on sensitizing EGFR TKI therapy, such as, erlotinib, gefitinib, afatinib (see "Osimertinib," page 520). ${ }^{37,39}$ Acquired resistance may also be associated with histologic transformation from NSCLC to SCLC and with epithelial to mesenchymal transition (see "Principles of Pathologic Review" in the complete version of these guidelines, at NCCN.org). ${ }^{40-42}$

DNA mutational analysis is the preferred method to assess for EGFR status. ${ }^{43-45}$ Various DNA mutation detection assays can be used to determine the EGFR mutation status in tumor cells. ${ }^{46}$ Direct sequencing of DNA corresponding to exons 18 to 21 (or just testing for exons 19 and 21) is a reasonable approach; however, more sensitive methods are available. ${ }^{21,44,47-49}$ Mutation screening assays using multiplex PCR (eg, Sequenom's MassARRAY system, SNaPshot Multiplex System) can detect $>50$ point mutations, including EGFR. ${ }^{50}$ Nextgeneration sequencing (NGS) can also be used to detect EGFR mutations. ${ }^{51}$

The predictive effects of the drug-sensitive EGFR mutations-exon 19del (LREA deletion) and L858R - are well defined. Patients with these mutations have a significantly better response to erlotinib, gefitinib, or afatinib. ${ }^{15}$ Retrospective studies have shown an objective response rate of approximately $80 \%$ with a median progression-free survival (PFS) of 13 months to single-agent EGFR TKI therapy in patients with a bronchioloalveolar variant of adenocarcinoma and a sensitizing EGFR mutation. ${ }^{52}$ A prospective study has shown that the objective response rate in North American patients with nonsquamous NSCLC and sensitizing EGFR mutations (53\% exon 19del [LREA deletion], 26\% L858R, and 21\% other mutations) is $55 \%$, with a median PFS of 9.2 months. ${ }^{53}$ EGFR mutation testing is not usually recommended in patients with pure squamous cell carcinoma (SCC) unless they never smoked, if only a small biopsy specimen (ie, not a surgical resection) was used to assess histology, or if the histology is mixed. ${ }^{54}$ Data suggest that EGFR mutations can occur in patients with adenosquamous carcinoma, which is harder to discriminate from SCC in small specimens. ${ }^{54}$

Data show that erlotinib, gefitinib, or afatinib (instead of standard first-line chemotherapy) should be used as first-line systemic therapy in patients with sensitizing EGFR mutations documented before first-line therapy. ${ }^{20,35,55-58}$ PFS is improved with use of EGFR TKI in patients with sensitizing EGFR mutations when compared with standard chemotherapy, although overall survival (OS) is not statistically different. ${ }^{20,35,36}$ Patients receiving erlotinib have fewer treatment-related severe side effects when compared with those receiving chemotherapy. ${ }^{35,59}$ A phase IV trial showed that gefitinib is safe and effective in patients with sensitizing EGFR mutations. ${ }^{16}$ Based on these data and the FDA approvals, erlotinib and gefitinib are recommended (category 1 ) as first-line systemic therapy in patients with sensitizing EGFR mutations. ${ }^{16,35}$ In a phase III randomized trial, patients receiving afatinib had decreased cough, decreased dyspnea, and improved health-related quality of life compared with those receiving cisplatin/ pemetrexed..$^{59}$ Based on these data and the FDA approval, afatinib is also recommended (category 1 ) as first-line systemic therapy in patients with sensitizing EGFR mutations. ${ }^{20}$ However, afatinib was potentially associated with 4 treatment-related deaths, whereas there were none in the chemotherapy group. ${ }^{20} \mathrm{~A}$ combined analysis (LUX 3 and LUX 6) reported a survival advantage in patients with exon 19del who received afatinib compared with chemotherapy. ${ }^{60}$

\section{ALK Gene Rearrangements}

An estimated 2\% to 7\% of patients with NSCLC have ALK gene rearrangements, approximately 10,000 of whom live in the United States. ${ }^{61}$ Patients with ALK rearrangements are resistant to EGFR TKIs but have similar clinical characteristics to patients with EGFR mutations (ie, adenocarcinoma histology, never smokers, light smokers) except that they are more likely to be men and may be younger. ${ }^{62}$ In these selected populations, estimates show that approximately $30 \%$ of patients will have ALK rearrangements. ${ }^{62,63}$ ALK rearrangements are not routinely found in patients with SCC. Although rare, patients with ALK gene rearrangements can have mixed squamous cell histology. ${ }^{64}$ It can be challenging to accurately determine histology in small biopsy specimens; thus, patients may have mixed squamous cell histology (or squamous components) instead of pure squamous cell. The NCCN panel recommends testing for ALK rearrangements if small biopsy specimens were used to assess histology, mixed histology was reported, or patients never smoked. A molecular diagnostic test 
(using fluorescence in situ hybridization [FISH]) has been approved by the FDA for detecting ALK rearrangements and is a prerequisite before treatment with crizotinib. Rapid prescreening can be performed with immunohistochemistry (IHC) to assess for ALK rearrangements; if positive, FISH analysis can confirm ALK positivity. ${ }^{65-74}$ NGS can also be used to assess whether ALK rearrangements are present, if the platform has been appropriately designed and validated to detect ALK rearrangements. ${ }^{75-77}$

Crizotinib-an inhibitor of ALK, ROS1, and some MET tyrosine kinases (high-level MET amplification or MET exon 14 skipping mutation) - is FDA-approved for patients with locally advanced or metastatic NSCLC who have ALK gene rearrangements (ie, ALK-positive disease) or ROS1 rearrangements. ${ }^{78-85}$ Crizotinib yields very high response rates $(>60 \%)$ when used in patients with advanced NSCLC who have ALK rearrangements, including those with brain metastases. ${ }^{61,81,86-88}$ Crizotinib has relatively few side effects (eg, eye disorders, edema, transient changes in renal function). ${ }^{87,89,90}$ However, a few patients have had life-threatening pneumonitis; crizotinib should be discontinued in these patients. ${ }^{83}$ Patients whose disease responds to crizotinib may have rapid improvement in symptoms (eg, cough, dyspnea, pain); median time to progression on crizotinib is approximately 7 months to 1 year. ${ }^{91,92}$

Randomized phase III trials have compared crizotinib with standard second-line (ie, subsequent) chemotherapy (PROFILE 1007) and with standard first-line therapy (PROFILE 1014). ${ }^{7,81,93}$ First-line therapy with crizotinib improved PFS, response rate ( $74 \%$ vs $45 \% ; P<.001$ ), lung cancer symptoms, and quality of life compared with chemotherapy (pemetrexed with either cisplatin or carboplatin). ${ }^{81}$ Based on this trial, crizotinib is recommended (category 1) for first-line therapy in patients with ALK-positive NSCLC (see NSCL-20, page 509). Subsequent therapy with crizotinib improved PFS (7.7 vs 3.0 months; $P<.001)$ and response rate $(65 \%$ vs $20 \% ; P<.001)$ compared with single-agent therapy (either docetaxel or pemetrexed) in patients with ALK-positive NSCLC whose disease had progressed after first-line chemotherapy. ${ }^{82}$ Based on this trial, crizotinib is recommended as subsequent therapy in patients with ALK-positive disease. The term subsequent therapy was recently substituted for second-line or beyond systemic therapy, because the line of therapy may vary depending on previous treatment with targeted agents.

For patients whose disease progresses on crizotinib, second-generation ALK inhibitors include ceritinib and alectinib; others are in development. ${ }^{94-104}$ Ceritinib is an orally active TKI of ALK, which also inhibits the insulin-like growth factor 1 (IGF-1) receptor but not MET. An expanded phase I trial showed that ceritinib was very active in 122 patients with locally advanced or metastatic NSCLC who have ALK gene rearrangements. ${ }^{98}$ The overall response rate to ceritinib was $56 \%$ in patients who had previously received crizotinib; the median PFS was 7 months. Based on this study, ceritinib was FDA-approved for patients with ALK-positive metastatic NSCLC that progresses on or who are intolerant of crizotinib. ${ }^{105}$ The NCCN panel recommends ceritinib for patients with ALK-positive metastatic NSCLC that has progressed on crizotinib or who are intolerant to crizotinib based on the data from Shaw et $\mathrm{al}^{98}$ and FDA approval. ${ }^{105}$ For the 2017 update (Version 5), the panel also recommends (category 1) ceritinib as first-line treatment for ALK-positive metastatic NSCLC based on a recent phase III trial (see "Ceritinib," page 521).

Alectinib is another oral TKI of ALK, which also inhibits RET but not MET or ROS1. Two phase II trials in patients with ALK rearrangements showed that alectinib was very active in those who had progressed on crizotinib. ${ }^{95,106}$ In the larger trial (138 patients) by Ou et $\mathrm{al},{ }^{95}$ patients on alectinib had a response rate of $50 \%$ (95\% CI, 41\%-59\%), and median response duration of 11.2 months (95\% CI, 9.6 months-not reached). For central nervous system (CNS) disease, the control rate was 83\% (95\% CI, $74 \%-91 \%)$ and the median response duration was 10.3 months (95\% CI, 7.6-11.2 months). Of 84 patients with baseline CNS metastases, 23 (27\%) had a complete CNS response to alectinib. Of 23 patients with baseline CNS metastases and no previous brain RT, 10 (43\%) had a complete CNS response to alectinib. Most adverse events (AEs) were only grade 1 to 2 (constipation, fatigue, and peripheral edema); 4 patients (3\%) had grade 3 dyspnea. One death due to intestinal perforation may have been related to alectinib. The other phase II trial in 87 patients with ALK-positive NSCLC that progressed on crizotinib reported that $48 \%$ of patients had an objective response to alectinib. ${ }^{106}$ Of 16 patients with baseline 
CNS metastases, 4 (25\%) achieved a complete response in the CNS; 11 had previously received RT. ${ }^{106}$ One treatment-related death occurred due to hemorrhage. Based on these studies, alectinib was FDAapproved for patients with ALK-positive metastatic NSCLC that progresses on or who are intolerant to crizotinib. ${ }^{107}$ The NCCN panel recommends alectinib (category 2A) for patients with ALK-positive metastatic NSCLC that has progressed on crizotinib or who are intolerant to crizotinib based on these 2 trials and FDA approval. ${ }^{95,106,107}$

ALK or ROS1 rearrangements and sensitizing EGFR mutations are generally mutually exclusive. ${ }^{68,108,109}$ Thus, erlotinib, gefitinib, and afatinib are not recommended as subsequent therapy in patients with ALK or ROS1 rearrangements who experience relapse on crizotinib. ${ }^{62,110}$ Likewise, crizotinib, ceritinib, and alectinib are not recommended for patients with sensitizing EGFR mutations whose disease relapses on erlotinib, gefitinib, or afatinib. For patients who experience disease progression on crizotinib, subsequent treatment for ALK-positive NSCLC includes ceritinib or alectinib (see "Ceritinib" and "Alectinib," pages 521 and 522, and NSCL-21, page 510). $87,95,111,112$ Continuing crizotinib may also be appropriate for patients whose disease progresses on crizotinib. ${ }^{113}$

\section{ROS1 Rearrangements}

Although ROS1 is a distinct receptor tyrosine kinase, it is very similar to ALK and members of the insulin receptor family (see "Principles of Pathologic Review" in the complete version of these guidelines, at NCCN.org). ${ }^{114,115}$ It is estimated that ROS1 gene rearrangements occur in approximately $1 \%$ to $2 \%$ of patients with NSCLC; they occur more frequently in younger women with adenocarcinoma who are never smokers and in those who are negative for EGFR mutations, KRAS mutations, and ALK gene rearrangements (also known as triple-negative). ${ }^{115-117}$ Crizotinib is very effective for patients with ROS1 rearrangements, with response rates of approximately $70 \%$, including complete responses. ${ }^{115}$ In 50 patients, crizotinib yielded a response rate of $66 \%$ (95\% CI, $51 \%-79 \%$ ); the median duration of response was 18 months. ${ }^{118}$ The FDA has approved crizotinib for patients with ROS1 rearrangements. ${ }^{18}$

For the 2017 update (Version 1), the NCCN panel moved the recommendation for ROS1 testing into the main algorithm (and deleted the footnote recommending ROS1 testing), added a new algorithm for ROS1, and added a new section on ROS1 to the molecular diagnostic studies section based on data showing the efficacy of crizotinib for patients with ROS1 rearrangements and on the FDA approval (see NSCL-22, page 511 and "Principles of Pathologic Review" in the complete version of these guidelines, at NCCN.org). ${ }^{80,115,118}$ Similar to testing for ALK rearrangements, testing for ROS1 is also performed using FISH. ${ }^{65,116,119-121}$ NGS can also be used to assess whether ROS1 rearrangements are present, if the platform has been appropriately designed and validated to detect ROS1 rearrangements. ${ }^{115}$ Because a companion diagnostic test has not been approved for ROS1, clinicians should use an appropriately validated test to detect ROS1. ${ }^{118}$ Alectinib and ceritinib are not effective in patients with ROS1 rearrangements whose disease becomes resistant to crizotinib. ${ }^{115}$ Studies are ongoing regarding new agents for patients with ROS1 rearrangements whose disease becomes resistant to crizotinib. ${ }^{122-125}$

\section{KRAS Mutations}

Data suggest that approximately $25 \%$ of patients with adenocarcinomas in a North American population have KRAS mutations; KRAS is the most common mutation. ${ }^{52,126-129}$ KRAS mutation prevalence is associated with cigarette smoking. ${ }^{130}$ Patients with KRAS mutations appear to have a shorter survival than those with wild-type KRAS; therefore, KRAS mutations are prognostic biomarkers. ${ }^{129,131,132}$ KRAS mutational status is also predictive of lack of therapeutic efficacy with EGFR TKIs; however, it does not appear to affect chemotherapeutic efficacy. ${ }^{52,128,133}$ KRAS mutations do not generally overlap with EGFR mutations, ALK rearrangements, or ROS1 rearrangements. ${ }^{68,134,135}$ Therefore, KRAS testing may identify patients who may not benefit from further molecular testing. ${ }^{133,136}$ Targeted therapy is not currently available for patients with KRAS mutations, although immune checkpoint inhibitors appear to be effective; MEK inhibitors are in clinical trials. ${ }^{97,127,137,138}$

\section{Targeted Therapies}

Specific targeted therapies are available for the treatment of advanced NSCLC. ${ }^{139-141}$ Erlotinib, gefitinib, and afatinib are small molecule inhibitors of EGFR; osimertinib targets T790M. Crizotinib is a small 
molecule inhibitor that targets ALK, ROS1, and MET (ie, high-level MET amplification, MET exon 14 skipping mutation). Ceritinib is a small molecule inhibitor that targets ALK and IGF-1 receptor. Alectinib is a small molecule inhibitor that targets ALK and RET. Erlotinib, gefitinib, afatinib, crizotinib, ceritinib, alectinib, and osimertinib are oral TKIs. Other targeted therapies are being developed (see "Emerging Targeted Agents for Patients With Genetic Alterations" in the complete version of these guidelines, at NCCN.org).

\section{EGFR TKIs}

Erlotinib and Gefitinib: In 2004, erlotinib was approved by the FDA for the treatment of patients with locally advanced or metastatic NSCLC after progression on at least one prior chemotherapy regimen. ${ }^{142}$ The FDA has also approved the use of erlotinib as first-line therapy in patients with sensitizing EGFR mutations. ${ }^{143}$ Erlotinib and gefitinib are recommended (category 1) in the NSCLC algorithm as first-line therapy in patients with advanced, recurrent, or metastatic nonsquamous NSCLC who have known active sensitizing EGFR mutations regardless of their PS (see NSCL-18, page 507). ${ }^{36,128,144,145}$ These recommendations are based on a phase III randomized trial (IPASS) in which patients with sensitizing EGFR mutations who received gefitinib had increased PFS (24.9\% vs $6.7 \%)$, response rate $(71.2 \%$ vs $47.3 \%)$, and quality of life, with fewer side effects (eg, neutropenia) compared with those receiving chemotherapy (carboplatin/paclitaxel). ${ }^{36}$ Updated results from the IPASS study showed that OS was similar in patients receiving gefitinib or chemotherapy regardless of sensitizing EGFR mutation status. ${ }^{146}$ However, these results probably occurred because patients who had been assigned to first-line chemotherapy were able to receive TKIs as subsequent therapy if they were found to have sensitizing EGFR mutations. A phase III randomized trial (EURTAC) in European patients with metastatic NSCLC and sensitizing EGFR mutations showed increased PFS and response rate for those receiving erlotinib compared with chemotherapy. ${ }^{35}$ For erlotinib, the median PFS was 9.7 months compared with 5.2 months for chemotherapy (hazard ratio [HR], 0.37; 95\% CI, 0.25-0.54; P<.0001). Fewer patients receiving erlotinib had severe AEs or died compared with those receiving chemotherapy.
TKIs are recommended in patients with metastatic NSCLC and sensitizing EGFR mutations, because quality of life is improved when compared with chemotherapy. Previously, erlotinib was commonly used in the United States in patients with sensitizing EGFR mutations because of restrictions on the use of gefitinib. However, gefitinib was reapproved by the FDA based on a phase IV study and is now available in the United States. ${ }^{16,147}$ Erlotinib and gefitinib are orally active TKIs that are very well tolerated by most patients. ${ }^{148,149}$ An analysis of 5 clinical trials in patients, mainly from the Western hemisphere $(n=223)$, with advanced NSCLC (stage IIIB or IV) found that those with sensitizing EGFR mutations who received TKIs had a $67 \%$ response rate and an OS of approximately 24 months. ${ }^{150}$ The TORCH trial suggested that EGFR mutation testing should be performed in patients with advanced nonsquamous NSCLC. ${ }^{151}$ Survival was increased in patients with wild-type EGFR who received first-line chemotherapy compared with those who received erlotinib first followed by subsequent chemotherapy (11.6 vs 8.7 months). The OPTIMAL trial reported that PFS was increased in patients with sensitizing EGFR mutations who received erlotinib. ${ }^{57,58}$ ASCO recommends that patients be tested for EGFR mutations. ${ }^{152}$ However, the ESMO Guidelines specify that only patients with nonsquamous NSCLC (eg, adenocarcinoma) be assessed for EGFR mutations. ${ }^{136,153}$ Patients with pure SCC are unlikely to have sensitizing EGFR mutations; however, those with adenosquamous carcinoma may have mutations. ${ }^{54}$

An updated study (CALGB 30406) compared erlotinib alone versus erlotinib/carboplatin/paclitaxel in patients (mainly Caucasian) with advanced NSCLC. ${ }^{154}$ The data showed that erlotinib alone was associated with fewer side effects in patients with sensitizing EGFR mutations when compared with erlotinib/chemotherapy. Thus, it is appropriate to interrupt or complete planned chemotherapy and switch to erlotinib, gefitinib, or afatinib therapy in patients found to have sensitizing EGFR mutations during chemotherapy (see NSCL-18, page 507).155 The NCCN Guidelines do not recommend adding erlotinib, gefitinib, or afatinib to current chemotherapy based on this CALGB study. ${ }^{154}$ Erlotinib, gefitinib, or afatinib may be continued in patients who have progressed if patients do not have multiple systemic symptomatic lesions (see "Continuation of 
Erlotinib, Gefitinib, or Afatinib After Progression," page 525).

A phase III trial (WJOG 5108L) assessed gefitinib versus erlotinib for patients with advanced lung cancer who had been previously treated with chemotherapy; most patients ( $72 \%$ ) were positive for EGFR mutations. ${ }^{156}$ The median PFS for gefitinib versus erlotinib was 8.3 and 10.0 months, respectively, in patients positive for EGFR mutations (HR, 1.093; 95\% CI, $0.879-1.358 ; P=.424)$. The main grade 3 or 4 toxicities included rash (gefitinib: $2.2 \%$ vs erlotinib: $18.1 \%)$ and increases in alanine aminotransferase (ALT)/aspartate aminotransferase (AST) levels (gefitinib: $6.1 \% / 13.0 \%$ vs erlotinib: $2.2 \% / 3.3 \%$ ).

Afatinib: A randomized phase III trial reported that first-line therapy with afatinib improved PFS compared with cisplatin/pemetrexed in patients with metastatic adenocarcinoma who have sensitizing EGFR mutations (11.1 vs 6.9 months; $P=.001$ ). ${ }^{20}$ The FDA approved afatinib for the first-line treatment of patients with metastatic NSCLC who have sensitizing EGFR mutations. ${ }^{19,157}$ Based on this phase III randomized trial and the FDA approval, the NCCN panel recommends afatinib for first-line therapy (category 1) in patients with metastatic nonsquamous NSCLC who have sensitizing EGFR mutations (see NSCL-18, page 507). ${ }^{17,20,112}$ Afatinib may also be continued in patients whose disease has progressed if they do not have multiple systemic symptomatic lesions (see "Continuation of Erlotinib, Gefitinib, or Afatinib After Progression," page 525). ${ }^{15}$ However, afatinib is not recommended as subsequent therapy based on a phase III randomized trial (see "SecondLine and Beyond (Subsequent) Systemic Therapy," page 526). ${ }^{158}$

A phase IIB trial assessed afatinib compared with gefitinib for first-line therapy in patients with metastatic adenocarcinoma and sensitizing EGFR mutations. ${ }^{159}$ The PFS was essentially the same in patients receiving afatinib compared with those receiving gefitinib (median PFS: 11.0 months [95\% CI, 10.6-12.9] with afatinib vs 10.9 months [95\% CI, 9.1-11.5] with gefitinib; HR, 0.73; 95\% CI, 0.570.95; $P=.017)$. These slight PFS differences are not clinically relevant and the NCCN Guidelines do not state that one EGFR TKI is more efficacious than another (see the NCCN Guidelines for NSCLC With Evidence Blocks, available at NCCN.org) ${ }^{156}$; OS data are not yet available. Patients receiving afatinib had more serious treatment-related side effects compared with those receiving gefitinib (11\% [17/160] for afatinib vs 4\% [7/159] for gefitinib). One patient receiving gefitinib died from treatment-related hepatic and renal failure; other deaths were not considered to be treatment-related (9\% vs $6 \%$ [15/160 vs $10 / 159]$ ). More patients receiving afatinib had diarrhea (13\% vs $1 \%$ ), whereas more patients receiving gefitinib had elevations in liver enzyme levels (0\% vs 9\%).

For the 2017 update (Version 1), the NCCN panel revised the afatinib evidence block for efficacy to highly effective (ie, the highest rating of 5), so the value is now the same as that for erlotinib and gefitinib (see the NCCN Guidelines for NSCLC With Evidence Blocks, available at NCCN.org). However, afatinib is rated as slightly less safe than erlotinib or gefitinib (ie, a rating of 3 for afatinib versus 4 for erlotinib and gefitinib).

Osimertinib: As previously mentioned, most patients with sensitizing EGFR mutations and metastatic NSCLC typically experience disease progression after approximately 9 to 13 months of erlotinib, gefitinib, or afatinib therapy. ${ }^{29,35-37}$ EGFR T790M is a mutation associated with acquired resistance to EGFR TKI therapy and has been reported in approximately 60\% of patients with disease progression after initial response to sensitizing EGFR TKI therapy. ${ }^{27-34}$ Osimertinib (AZD9291) is an oral TKI that inhibits both EGFR-sensitizing mutations and T790M.

A phase III randomized trial assessed osimertinib versus platinum-pemetrexed chemotherapy in patients with EGFR T790M-positive metastatic NSCLC. Data show that osimertinib increased PFS compared with chemotherapy (10.1 vs 4.4 months; HR, 0.30; 95\% CI, 0.23-0.41; P<.001). ${ }^{37}$ PFS was also increased in patients with CNS metastases who received osimertinib (8.5 vs 4.2 months; HR, 0.32; 95\% CI, 0.21-0.49). In addition, the objective response rate was improved with osimertinib (71\%; 95\% CI, 65\%-76\%) compared with chemotherapy (31\%; 95\% CI, 24\%-40\%) (odds ratio for objective response, 5.39; 95\% CI, 3.47-8.48; $\mathrm{P}<.001)$. The disease control rate is approximately $93 \%$ with osimertinib (95\% CI, 90\%-96\%) and approximately $74 \%$ with chemotherapy (95\% CI, 66\%-81\%). Patients receiving osimertinib had fewer grade $\geq 3$ AEs compared with those receiving chemotherapy $(23 \%$ vs $47 \%$ [63/279 vs 64/136]); however, there were 4 fatal events with osimertinib (respiratory failure [2], 
pneumonitis, ischemic stroke) and 1 with chemotherapy (hypovolemic shock).

Data from a multicenter, single-arm phase II clinical trial indicate that osimertinib is associated with a response rate of approximately $61 \%(78 / 127$; 95\% CI, 52-70), PFS of 9.6 months (95\% CI, 8.3not reached), and disease control rate of approximately 95\% (121/127; 95\% CI, 90-98) in patients with EGFR T790M whose disease has progressed on sensitizing EGFR TKI therapy; 13\% (33/253) of patients had drug-related grade $\geq 3$ AEs with 1 fatal event from pneumonia possibly related to treatment. ${ }^{39,160,161}$ In patients without EGFR T790M, the response rate was $21 \%(13 / 61 ; 95 \% \mathrm{CI}, 12-34)$ and the PFS was 2.8 months (95\% CI, 2.1-4.3). ${ }^{39}$

The FDA has approved osimertinib for patients with metastatic EGFR T790M-positive NSCLC, as detected by an FDA-approved test, whose disease has progressed on or after EGFR TKI therapy. Based on the data and FDA approval, the NCCN panel recommends osimertinib (category 1) as subsequent therapy for patients with metastatic EGFR T790Mpositive NSCLC whose disease has progressed on erlotinib, gefitinib, or afatinib therapy (see "Second-Line and Beyond (Subsequent) Systemic Therapy," page 526). For the 2017 update (Version 4), the NCCN panel revised the recommendation to category 1 (from category 2A) for osimertinib in patients with EGFR T790M-positive metastatic NSCLC based on the phase 3 randomized trial. ${ }^{37}$ T790M can be assessed using an FDA-approved test or other validated laboratory test done in a CLIAapproved laboratory. Data suggest that plasma genotyping (also known as liquid biopsy or plasma biopsy) may be considered instead of tissue biopsy to detect whether patients have T790M; however, if the plasma biopsy is negative, then tissue biopsy is recommended if feasible. ${ }^{162,163}$ For the 2017 update (Version 4), the NCCN panel now also recommends osimertinib (category 1) for patients with T790M who have experienced progression with symptomatic brain metastases based on data showing an improvement. ${ }^{37,164-167}$

\section{ALK/ROS1 Inhibitors}

Crizotinib: Crizotinib is approved by the FDA for patients with locally advanced or metastatic NSCLC who are positive for the ALK gene rearrangement. ${ }^{78}$ The approval is based on a phase II trial that showed dramatic response rates $(>80 \%)$ to crizotinib in patients whose disease had previously progressed. ${ }^{83,84}$ Patients receiving crizotinib reported clinically significant improvements in pain, dyspnea, and cough. A phase III trial compared first-line crizotinib versus chemotherapy in patients with ALK rearrangements; patients receiving crizotinib had improved PFS, quality of life, and response rates compared with those receiving chemotherapy. ${ }^{81}$ The NCCN panel recommends first-line therapy with crizotinib (category 1 ) based on the results of this phase III trial and the FDA approval; the panel also feels that crizotinib is appropriate for patients with PS 0 to 4. Crizotinib may also be continued for patients with ALK rearrangements whose disease has progressed if patients do not have multiple systemic symptomatic lesions. ${ }^{82}$

Crizotinib is also very effective for patients with ROS1 rearrangements with response rates of approximately $70 \%$, including complete responses (see "ROS1 Rearrangements," page 518). ${ }^{115,118}$ For the 2017 update (Version 1), the NCCN Panel moved the recommendation for ROS1 testing into the main algorithm (and deleted the footnote recommending ROS1 testing), added a new algorithm for ROS1, and added a new section on ROS1 to the molecular diagnostic studies section based on data showing the efficacy of crizotinib for patients with ROS1 rearrangements and on the FDA approval (see "Principles of Pathologic Review" in the complete version of these guidelines, at NCCN. org). ${ }^{80,115,118}$ Alectinib and ceritinib are not effective in patients with ROS1 rearrangements whose disease becomes resistant to crizotinib.

Ceritinib: Ceritinib is approved by the FDA for patients with ALK-positive metastatic NSCLC who have progressed on or are intolerant to crizotinib. ${ }^{105}$ The approval is based on an expanded phase I study (ASCEND-1) showing overall response rates of 56\% to ceritinib in patients (92/163) who had previously received crizotinib; the median duration of response was 8.3 months (range, 6.8-9.7 months).98,168 Common grade 3/4 AEs included increased alanine aminotransferase (73 [30\%] patients) and increased aspartate aminotransferase $(25[10 \%]) .{ }^{168}$ Some patients with CNS lesions experienced response to ceritinib. Based on the study and the FDA approval, the NCCN panel recommends ceritinib as subsequent therapy for patients with ALK-positive NSCLC that progressed after crizotinib; patients who do not 
tolerate crizotinib may be switched to ceritinib or alectinib. A phase II trial (ASCEND-2) assessed ceritinib in patients who had previously received at least $\geq 2$ treatments, had experienced progression on crizotinib, and had brain metastases. ${ }^{169}$ The overall response rate was 38\%; the duration of response was 9.7 months (95\% CI, 7.1-11.1 months). ${ }^{169}$ The intracranial overall response rate was 45.0\% (95\% CI, $23.1 \%-68.5 \%)$.

A recent phase III trial assessed ceritinib versus platinum-based chemotherapy as first-line therapy for patients with ALK-positive metastatic NSCLC. ${ }^{170}$ The data show that PFS was improved when using ceritinib compared with platinum-based chemotherapy; the median PFS was 16.6 months $(95 \% \mathrm{CI}$, 12.6-27.2) for ceritinib and 8.1 months (95\% CI, 5.8-11.1) for chemotherapy (HR, 0.55; 95\% CI, $0.42-0.73 ; P<.00001)$. For ceritinib, common adverse events included diarrhea (85\% [160/189] of patients), nausea (69\% [130/189]), vomiting (66\% [125/189), and an increase in alanine aminotransferase (60\% [114/189]). For chemotherapy, common adverse events included nausea (55\% [97/175] of patients), vomiting (36\% [63/175]), and anemia (35\% [62/175]). For the 2017 update (Version 5), the NCCN panel now recommends ceritinib as first-line therapy (category 1) for patients with ALK-positive metastatic NSCLC based on this trial.

Alectinib: Alectinib is approved by the FDA for patients with ALK-positive metastatic NSCLC who have experienced progression on or are intolerant to crizotinib. ${ }^{107}$ The approval is based on 2 phase II trials showing overall response rates of $48 \%$ to $50 \%$ to alectinib in patients who had previously received crizotinib. ${ }^{95,106}$ In the larger trial by $\mathrm{Ou}$ et al, ${ }^{95}$ the control rate for CNS disease was $83 \%$ (95\% CI, $74 \%-91 \%)$, and the median duration of response was 10.3 months (95\% CI, 7.6-11.2 months). Of 84 patients with baseline CNS metastases, 23 (27\%) had a complete CNS response. Of 23 patients with baseline CNS metastases and without previous brain RT, 10 (43\%) had a complete CNS response to alectinib. Based on these trials and the FDA approval, the NCCN panel recommends alectinib as subsequent therapy for patients with ALK-positive NSCLC that has progressed after crizotinib; patients who do not tolerate crizotinib may be switched to alectinib or ceritinib.

\section{Immunotherapeutic Agents}

Human immune-checkpoint-inhibitor antibodies inhibit the PD-1 receptor or PD-1 ligand (PD-L1), which improves antitumor immunity; PD-1 receptors are expressed on activated cytotoxic T-cells. ${ }^{171-173}$ The NCCN panel recommends immune checkpoint inhibitors as preferred agents for subsequent therapy based on improved OS rates, longer duration of response, and fewer AEs when compared with cytotoxic chemotherapy. ${ }^{171,174-176}$ Immune checkpoint inhibitors are associated with a delay in benefit compared with targeted therapy or cytotoxic chemotherapy. Pseudoprogression has been reported; therefore, traditional RECIST criteria may not be applicable. ${ }^{177}$ Current or former smoking status correlated with the response rate to immune checkpoint inhibitors. ${ }^{171,178-180}$ Data suggest that mismatch repair deficiency is associated with response to immune checkpoint inhibitors. ${ }^{181}$ Immune-related AEs, such as pneumonitis, may occur with immune checkpoint inhibitors. ${ }^{173,178,182-189}$ Intravenous high-dose corticosteroids should be administered based on the severity of the reaction for patients with immune-mediated AEs. Immune checkpoint inhibitors should be discontinued for patients with severe or life-threatening pneumonitis and should be withheld or discontinued for other severe or life-threatening immune-mediated AEs when indicated (see prescribing information).

Nivolumab: The NCCN panel recommends nivolumab (category 1 ) as subsequent therapy for patients with metastatic nonsquamous NSCLC that has progressed on or after first-line chemotherapy based on data from a phase III randomized trial (CheckMate-057) and FDA approval (see NSCL-24, page 513). ${ }^{171,190}$ Nivolumab inhibits PD-1 receptors. ${ }^{175}$ The category 1 recommendation for nivolumab is based on the published data from CheckMate-057 and FDA approval of nivolumab for patients with metastatic nonsquamous NSCLC. For patients receiving nivolumab, median OS was 12.2 months compared with 9.4 months for docetaxel (HR, 0.73; 95\% CI, 0.59-0.89; $P=.002)$. ${ }^{171}$ The median duration of response was 17.2 months with nivolumab compared with 5.6 months for docetaxel. At 18 months, the OS rate was 39\% (95\% CI, 34\%-45\%) with nivolumab compared with $23 \%$ (95\% CI, 19\%-28\%) with docetaxel. Fewer grade 3 to 5 AEs were reported for nivolumab (10\%) compared with docetaxel (54\%) in the CheckMate-057 trial. 
Although many patients with metastatic nonsquamous NSCLC benefit from nivolumab, those whose tumors have PD-L1 staining of $1 \%$ to $\geq 10 \%$ have an OS of 17 to 19 months compared with 8 to 9 months for docetaxel. For patients who did not have PD-L1 expression, there was no difference in OS for nivolumab versus docetaxel; however, nivolumab was associated with a longer duration of response and fewer side effects. To help clinicians determine which patients with nonsquamous NSCLC may benefit most from treatment with nivolumab, the FDA approved a complementary diagnostic biomarker test to assess for PD-L1 protein expression. ${ }^{191}$ Testing for PD-L1 is not required for prescribing nivolumab but may provide useful information. ${ }^{192}$

The NCCN panel also recommends (category 1) nivolumab as subsequent therapy for patients with metastatic squamous cell NSCLC that has progressed on or after first-line chemotherapy based on data from a phase III randomized trial (CheckMate-017), FDA approval, and results of a phase II trial (see NSCL25, page 514). ${ }^{175,186}$ In the CheckMate-017 trial, the median OS was 9.2 months with nivolumab compared with 6.0 months for docetaxel. ${ }^{175}$ Patients had a response rate of $20 \%$ with nivolumab compared with $9 \%$ for docetaxel $(P=.008)$. PD-L1 expression was not associated with response to nivolumab in patients with squamous cell NSCLC. There were fewer grade 3/4 AEs with nivolumab (7\%) compared with docetaxel (55\%). No patients died in the nivolumab arm versus 3 deaths in the docetaxel arm.

Pembrolizumab: For the 2017 updates (Versions 1 and 2), the NCCN panel recommends pembrolizum$\mathrm{ab}$ (category 1) as first-line therapy for patients with PD-L1 expression levels of $\geq 50 \%$ and with negative or unknown tests results for EGFR mutations, ALK rearrangements, and ROS1 rearrangements based on a phase III randomized trial (Keynote-024) comparing pembrolizumab versus platinum-based chemotherapy; the FDA approved pembrolizumab for first-line therapy based on this trial (see NSCL-23, page 512). ${ }^{193}$ At 6 months, the OS rate was $80.2 \%$ in the pembrolizumab group versus $72.4 \%$ in the chemotherapy group (HR for death, 0.60; 95\% CI, $0.41-0.89 ; P=.005)$. Reponses were higher in the pembrolizumab group than in the chemotherapy group (44.8\% vs 27.8\%). ${ }^{193}$ There were fewer severe treatment-related AEs (grades 3-5) in patients receiving pembrolizumab compared with those receiving chemotherapy ( $26.6 \%$ vs $53.3 \%$ ).

For the 2017 update (Version 1), the NCCN panel recommends (category 2A) IHC testing for PD-L1 expression before first-line treatment in patients with metastatic NSCLC with negative or unknown tests results for EGFR mutations, ALK rearrangements, and ROS1 rearrangements. ${ }^{194}$ Although it is not an optimal biomarker, PD-L1 expression is currently the best available biomarker to assess whether patients are candidates for pembrolizumab. ${ }^{195,196}$ PD-L1 expression is continuously variable and dynamic; thus, a cutoff value for a positive result is artificial. Patients with PD-L1 expression levels just below and just above $50 \%$ will probably have similar responses. ${ }^{195}$ Unique anti-PD-L1 IHC assays are being developed for each one of the different immune checkpoint inhibitors currently in clinical trials. ${ }^{192,195}$ The definition of a positive PD-L1 test result varies depending on which biomarker assay is used. ${ }^{192}$

Ideally, PD-L1 expression levels are assessed in patients with negative or unknown test results for EGFR mutations, ALK rearrangements, or ROS1 rearrangements. Every effort needs to be made to establish the genetic alteration status. However, if the risk of biopsy is high and genetic alteration testing is not feasible and therefore technically unknown, then it is appropriate to test for PD-L1 expression levels. There are blood assays to evaluate for EGFR mutations and ALK rearrangements, although they are less sensitive than tissue assays.

The NCCN panel also recommends pembrolizumab (category 1) as subsequent therapy for patients with metastatic nonsquamous or squamous NSCLC and PD-L1 expression based on the randomized phase II/III trial (KEYNOTE-010), the phase I KEYNOTE-001 trial, and FDA approval (see NSCL24, page 513 and NSCL-25, page 514). ${ }^{176,179,197}$ Pembrolizumab inhibits the PD-1 receptor. ${ }^{193}$

A randomized phase II/III trial (KEYNOTE-010) assessed pembrolizumab in patients with previously treated advanced nonsquamous and squamous NSCLC who were PD-L1 positive $(\geq 1 \%)$; most patients were current or former smokers. ${ }^{176}$ There were 3 arms in this trial: pembrolizumab at $2 \mathrm{mg} /$ $\mathrm{kg}$, pembrolizumab at $10 \mathrm{mg} / \mathrm{kg}$, and docetaxel at $75 \mathrm{mg} / \mathrm{m}^{2}$ every 3 weeks. The median OS was 10.4 months for the lower dose of pembrolizumab, 12.7 months for the higher dose, and 8.5 months for 
docetaxel. OS was significantly longer for both doses of pembrolizumab compared with docetaxel (pembrolizumab, 2 mg/kg: HR, 0.71; 95\% CI, 0.58-0.88; $P=.0008$ ) (pembrolizumab, $10 \mathrm{mg} / \mathrm{kg}$ : HR, 0.61; CI, $0.49-0.75 ; P<.0001)$. For patients with at least $50 \%$ PD-L1 expression in tumor cells, OS was also significantly longer at either dose of pembrolizumab compared with docetaxel (pembrolizumab, $2 \mathrm{mg} / \mathrm{kg}$ : 14.9 vs 8.2 months; HR, 0.54; 95\% CI, 0.38-0.77; $P=.0002$ and pembrolizumab, $10 \mathrm{mg} / \mathrm{kg}: 17.3$ vs 8.2 months; HR, 0.50; CI, 0.36-0.70; P<.0001). When compared with docetaxel, there were fewer grade 3 to 5 treatment-related AEs at either dose of pembrolizumab (pembrolizumab, $2 \mathrm{mg} / \mathrm{kg}$ : $13 \%$ of patients [43/339]; pembrolizumab, $10 \mathrm{mg} / \mathrm{kg}: 16 \%$ [55/343]; and docetaxel: 35\% [109/309]). A total of 6 treatment-related deaths occurred in patients receiving pembrolizumab (3 at each dose) and 5 treatmentrelated deaths occurred in the docetaxel arm.

A phase I trial (KEYNOTE-001) assessed the safety and efficacy of pembrolizumab for patients with metastatic NSCLC. ${ }^{179}$ Among all patients, the response rate was $19 \%$, the median duration of response was 12.5 months, PFS was 3.7 months, and median OS was 12.0 months. Patients with a PDL1 expression score of at least $50 \%$ had a response rate of $45 \%$, a PFS of 6.3 months, and OS was not reached. Less than $10 \%$ of patients had serious toxicity of grade $\geq 3$.

The FDA approved pembrolizumab as subsequent therapy for patients with metastatic NSCLC whose disease has progressed after platinum-based chemotherapy if their tumors express PD-L1. ${ }^{197}$ The FDA has approved a companion diagnostic biomarker test for assessing PD-L1 expression and determining which patients are eligible for pembrolizumab therapy. Other immunotherapeutic agents are being investigated. ${ }^{174,198-200}$

Atezolizumab: For the 2017 update (Version 4), the NCCN panel revised the recommendation to category 1 for atezolizumab as subsequent therapy for patients with metastatic nonsquamous or squamous cell NSCLC based on a recent phase III trial ${ }^{178}$; previously this was a category $2 \mathrm{~A}$ recommendation based on preliminary data from a phase III randomized trial, data from a phase II trial, and recent FDA approval (see NSCL-24, page 513 and NSCL-25, page 514). ${ }^{200,201}$ Testing for PD-L1 expression levels is not required for prescribing atezolizumab but may provide useful information. Atezolizumab inhibits PD-L1. ${ }^{200}$

A phase III randomized trial (OAK) assessed atezolizumab versus docetaxel alone in patients with metastatic NSCLC that had progressed during or after systemic therapy. ${ }^{178,201}$ Most patients were current or former smokers and had received platinum-based chemotherapy; few patients (10\%) had EGFR mutations, and ALK rearrangements were not reported. ${ }^{178,201}$ Data show that patients with nonsquamous NSCLC who received atezolizumab had improved OS compared with those receiving docetaxel (15.6 vs 11.2 months; HR, 0.73 [0.6-0.89]; P=.0015). OS was only slightly improved in patients with squamous cell NSCLC receiving atezolizumab versus docetaxel (8.9 vs 7.7 months; HR, 0.73 [0.54-0.98]; P=.038); however, there were fewer patients in the squamous NSCLC group compared with the nonsquamous group (222 vs 628). There were fewer treatment-related severe AEs (grades 3/4) for atezolizumab versus docetaxel (15\% vs $43 \%$ [90/609 vs 247/578]). For the 2017 update (Version 4), the NCCN panel revised the atezolizumab evidence block for efficacy to a rating of 4 (very effective) from the previous rating of 3 (moderately effective) (see the NCCN Guidelines for NSCLC With Evidence Blocks, available at NCCN.org).

\section{Treatment of Recurrences and Distant Metastases}

For patients with recurrent and metastatic disease, the NCCN Guidelines recommend that histologic subtype should be determined before therapy so that the best treatment can be selected (see NSCL-17, page 506). ${ }^{202}$ In addition, testing for genetic alterations (ie, driver events) is recommended in patients with NSCLC, because targeted therapy has been shown to decrease tumor burden, decrease symptoms, and dramatically improve the quality of life for patients with specific genetic alterations. The number of available targeted agents is increasing. Several targeted agents, such as erlotinib, gefitinib, afatinib, and crizotinib, have category 1 recommendations for first-line therapy based on larger trials. ${ }^{155}$

EGFR mutation testing (category 1) is recommended in patients with nonsquamous NSCLC (ie, adenocarcinoma, large cell carcinoma) or NSCLC not otherwise specified (NOS), because erlotinib, gefitinib, and afatinib (category 1 for all) are recom- 
mended for patients who are positive for sensitizing EGFR mutations (see NSCL-17, page 506 and NSCL-18, page 507). ${ }^{15,36,56,128,203}$ Testing for ALK rearrangements (category 1 ) is also recommended in patients with nonsquamous NSCLC, because crizotinib is recommended (category 1 ) for patients who are positive for ALK rearrangements. ${ }^{70,204}$ Crizotinib is also recommended for patients who are positive for ROS1 rearrangements and MET amplification. ${ }^{115,116,205,206}$ For the 2017 update (Version 1), the NCCN panel added a recommendation for testing for ROS1 rearrangements (category 2A). Testing for ROS1 has typically been performed using FISH; however, a validated NGS platform that can detect this gene fusion may also be used. ${ }^{120}$ The NCCN panel recommends that EGFR mutation testing be performed as part of broad molecular profiling (eg, multiplex mutation screening assays or NGS). Testing for ALK gene rearrangements can be performed with FISH or with NGS if the platform is validated and can identify gene fusions..$^{51,126,207}$ For the 2017 update (Version 1), the NCCN panel also added a recommendation for upfront PD-L1 expression testing before first-line therapy in patients with metastatic NSCLC to assess whether patients are candidates for immune checkpoint inhibitors (see "Pembrolizumab," page 523).

As previously mentioned, recommendations from an international panel suggest that general histologic categories be avoided (eg, NSCLC), because more effective treatment can be selected when the histology is known. ${ }^{208}$ Patients with pure squamous cell carcinoma do not seem to have ALK rearrangements, ROS1 rearrangements, or sensitizing EGFR mutations; therefore, routine testing is not recommended in these patients. ${ }^{54,209-211}$ However, testing for ALK rearrangements, ROS1 rearrangements, or EGFR mutations can be considered in patients with squamous cell carcinomas who never smoked and those whose histology was determined using small biopsy specimens or mixed histology specimens. ${ }^{54}$ Treatment recommendations and eligibility criteria for patients with nonsquamous NSCLC (or NSCLC NOS) who are negative or unknown for ALK or ROS1 rearrangements, sensitizing EGFR mutations, or PD-L1 expression are described in the complete version of the NCCN Guidelines. Treatment recommendations and eligibility criteria for patients with squamous cell carcinoma are also described in the complete version of the NCCN Guidelines.

\section{Continuation of Erlotinib, Gefitinib, or Afatinib After Progression}

Previously, erlotinib was commonly used in the United States in patients with sensitizing EGFR mutations because of restrictions on the use of gefitinib. However, gefitinib was reapproved by the FDA based on a phase IV study and is now available in the United States. ${ }^{16}$ Patients may continue to derive benefit from erlotinib, gefitinib, or afatinib after disease progression; discontinuation of these TKIs leads to more rapid progression of disease (symptoms, tumor size, and FDG-avidity on PET scan). ${ }^{212}$ This strategy mirrors the experience in other oncogene-addicted cancers, particularly HER2-amplified breast cancer. In women with HER2-amplified breast cancer who have had disease progression on trastuzumab, improved radiographic response rate, time to progression, and OS are observed when conventional chemotherapy is added to trastuzumab. ${ }^{213}$

After development of acquired resistance in patients with lung adenocarcinoma and sensitizing EGFR mutations, erlotinib, gefitinib, or afatinib may be continued, but osimertinib is also an option for select patients; local therapy should be considered (eg, stereotactic radiosurgery to brain metastases or other sites, SABR for thoracic disease). ${ }^{214-217}$ The NCCN panel recommends continuing erlotinib, gefitinib, or afatinib and considering local therapy in patients with asymptomatic progression; however, treatment varies for patients with symptomatic progression (see NSCL-19, page 508). ${ }^{218-220}$ For the 2017 updates (Versions 1 and 4), the NCCN panel revised the recommendations for patients with sensitizing EGFR mutations whose disease has progressed on erlotinib, gefitinib, or afatinib. Osimertinib is now recommended (category 1 ) for patients with symptomatic brain metastases. ${ }^{37}$ Another option is to continue use of erlotinib, gefitinib, or afatinib for these patients; however, additional therapy may be added or substituted (eg, local therapy, systemic therapy). Firstline systemic therapy options are recommended for patients with multiple symptomatic lesions who are negative for T790M; osimertinib is recommended (category 1) for patients positive for T790M.

Accumulating data suggest how cancers become resistant to EGFR inhibitors. ${ }^{221}$ The most common 
known mechanism is the acquisition of T790M (which is a secondary mutation in EGFR), which renders the kinase resistant to erlotinib, gefitinib, or afatinib. ${ }^{222,223}$ Therefore, if patients are T790Mpositive, osimertinib is recommended (category 1 ) and erlotinib, gefitinib, or afatinib are discontinued. Amplification of the MET oncogene is another validated resistance mechanism. To overcome resistance, EGFR must still be inhibited. In the case of MET amplification, new inhibitors must be added to the EGFR inhibitor; however, EGFR inhibition is still required to induce remission. Furthermore, data by Riely et $\mathrm{a}^{1212}$ show that when cancers start to progress, which were once sensitive to EGFR inhibitors, discontinuation of the EGFR TKI can lead to a much more accelerated progression of the cancer. ${ }^{224}$ Thus, continuing EGFR TKIs is beneficial in many patients even after they develop resistance to EGFR TKIs. ${ }^{217}$

\section{Second-Line and Beyond (Subsequent) Systemic Therapy}

The phrase subsequent therapy was substituted for the terms second-line, third-line, and beyond systemic therapy, because the line of therapy may vary depending on previous treatment with targeted agents. Subsequent systemic therapy regimens for patients who have disease progression during or after first-line therapy are described in the NSCLC algorithm and depend on the specific genetic alteration, the histologic subtype, and whether the patient has symptoms (see the complete version of these guidelines, available at NCCN.org). ${ }^{225-234}$ For the 2017 update (Version 1), the NCCN panel now recommends response assessment of known sites of disease with CT (with contrast) every 6 to 12 weeks in patients receiving subsequent therapy. Note that traditional RECIST 1.1 criteria are used to assess response for most types of systemic therapy, but different response criteria may be useful for assessing response in patients receiving immunotherapy. ${ }^{235-237}$

The NCCN panel recommends immune checkpoint inhibitors as preferred agents for subsequent therapy in patients with metastatic NSCLC based on improved survival rates, longer duration of response, and fewer AEs compared with cytotoxic chemotherapy (see "Nivolumab," "Pembrolizumab," and "Atezolizumab," pages 522, 523, and 524, respectively). ${ }^{11,175,201}$ Human immune-checkpoint-inhibitor antibodies inhibit the PD-1 receptor or PD-L1, which improves antitumor immunity; PD-1 receptors are expressed on activated cytotoxic T cells. ${ }^{171-173}$ The NCCN panel recommends nivolumab (category 1 ) as subsequent therapy for patients with metastatic nonsquamous or squamous NSCLC based on a phase III randomized trial (CheckMate-057) and FDA approval. ${ }^{171}$ The NCCN panel recommends pembrolizumab (category 1) as subsequent therapy for patients with metastatic nonsquamous or squamous NSCLC and PD-L1 expression based on a phase II/III randomized trial (KEYNOTE-010) trial, KEYNOTE-001 trial, and FDA approval. ${ }^{176,179}$ The NCCN panel also recommends atezolizumab (category 1) as subsequent therapy for patients with metastatic nonsquamous or squamous NSCLC based on a phase III randomized trial (OAK), data from a phase II trial (POPLAR), and FDA approval. ${ }^{178,200,201}$

The NCCN panel recommends osimertinib (category 1) as subsequent therapy for patients with metastatic EGFR T790M-positive NSCLC that has progressed on erlotinib, gefitinib, or afatinib therapy based on data and FDA approval (see "Osimertinib," page 520)..$^{37,39}$ Osimertinib (AZD9291) is an oral TKI that inhibits both EGFR-sensitizing mutations and T790M. Data from a phase III trial report that osimertinib is associated with a response rate of approximately $71 \%$ and disease control rate of approximately 93\% (95\% CI, 90\%-96\%) in patients whose disease has progressed on sensitizing EGFR TKI therapy; $23 \%$ of patients had drug-related grade $\geq 3$ AEs with 4 fatal events. ${ }^{37,39,160,161}$ The FDA has approved osimertinib for patients with metastatic EGFR T790M-positive NSCLC, as detected by an FDA-approved test, that has progressed on or after EGFR TKI therapy. Most patients with sensitizing EGFR mutations and metastatic NSCLC typically experience disease progression after approximately 9 to 13 months of erlotinib or gefitinib therapy. ${ }^{35-37}$ EGFR T790M is associated with acquired resistance to TKI therapy and has been reported in approximately $60 \%$ of patients with disease progression after initial response to sensitizing EGFR TKI therapy. ${ }^{27-34}$ T790M can be assessed using an FDA-approved test or other validated laboratory test performed in a CLIA-approved laboratory.

For patients with sensitizing EGFR mutations who progress during or after first-line targeted therapy, recommended therapy depends on whether the progression is asymptomatic or symptomatic and 
includes continuing erlotinib, afatinib, or gefitinib with (or without) local therapy; osimertinib; or a first-line systemic therapy regimen for either nonsquamous or squamous cell NSCLC (such as cisplatin/pemetrexed or cisplatin/gemcitabine, respectively). For the 2017 update (Version 4), the NCCN panel now also recommends osimertinib (category 1 ) for patients with T790M who have brain metastases. ${ }^{37,164-166}$ Data suggest that an afatinib/cetuximab regimen may be useful for patients whose disease has progressed after receiving EGFR TKI therapy and chemotherapy. ${ }^{238}$ Patients with T790M-positive and T790M-negative tumors had a similar response rate to an afatinib/cetuximab regimen (32\% vs $25 \%$; $P=.341$ ). The NCCN panel recommends (category 2A) considering an afatinib/cetuximab regimen for patients whose disease has progressed after receiving EGFR TKIs and chemotherapy based on these data.

Among patients with sensitizing EFGR mutations, no improvement in OS has been noted in the phase III trials assessing pembrolizumab, nivolumab, or atezolizumab compared with docetaxel, but there were not enough patients with these mutations to determine whether there were statistically significant differences (see next paragraph). ${ }^{171,176,201,239}$ Immunotherapy was not worse than chemotherapy and was better tolerated. In the phase III trials for pembrolizumab, nivolumab, or atezolizumab versus docetaxel as subsequent therapy for patients with metastatic NSCLC, subset analyses were performed in patients with EGFR mutations to determine the best subsequent therapy. ${ }^{171,176,201}$ The HRs for OS do not favor docetaxel over nivolumab (HR, 1.18; CI, 0.69-2.0), pembrolizumab (HR, 0.88; CI, 0.45-1.7), or atezolizumab (HR, 1.24; CI, 0.7-2.2); the CIs for the HRs are wide probably because there were so few patients with EGFR mutations. The HRs for PFS do favor docetaxel for patients with EGFR mutations compared with either pembrolizumab (HR, 1.79; CI, 0.94-3.42) or nivolumab (HR, 1.46; CI, 0.90-2.37). But again, the CIs are wide. The evidence is weak for recommending docetaxel, pembrolizumab, nivolum$\mathrm{ab}$, or atezolizumab as subsequent therapy for patients with EGFR mutations. Data suggest that patients with EGFR mutations or ALK rearrangements have a low response rate to PD-1 or PD-L1 inhibitors when compared with patients without these genetic alterations (response rate, $3.6 \%$ vs $23 \%$, respectively). 239
For patients with ALK rearrangements whose disease progresses during or after first-line targeted therapy, recommended therapy also depends on whether the progression is asymptomatic or symptomatic and includes continuing crizotinib with (or without) local therapy; ceritinib; alectinib; or a first-line systemic therapy regimen for either nonsquamous or squamous cell NSCLC. After further progression on subsequent targeted therapy, first-line combination chemotherapy options for nonsquamous NSCLC or squamous cell carcinoma are recommended for patients with PS of 0 to 1 , such as cisplatin/pemetrexed or cisplatin/gemcitabine (both are category 1), respectively. ${ }^{139,240}$ Other chemotherapy options are also recommended for patients with PS 2, such as docetaxel (see "Systemic Therapy for Advanced or Metastatic Disease" in the complete version of these guidelines, at NCCN.org).

Most patients with NSCLC do not have ALK rearrangements, ROS1 rearrangements, or sensitizing EGFR mutations. For patients with all histologic subtypes and PS of 0 to 2 but without these genetic alterations who have disease progression during or after first-line therapy, recommended subsequent systemic therapy options include nivolumab (category 1 ), pembrolizumab (category 1 ), atezolizumab (category 1), docetaxel with (or without) ramucirumab, or gemcitabine if not already given; pemetrexed is recommended for patients with nonsquamous NSCLC. For the 2017 update (Version 4 ), the NCCN panel revised the recommendation for atezolizumab to category 1 (from category 2A) as subsequent therapy. The NCCN panel recommends immune checkpoint inhibitors-nivolumab, pembrolizumab, and atezolizumab-as preferred options for subsequent therapy for all histologic subtypes based on improved survival rates, longer duration of response, and fewer AEs compared with cytotoxic chemotherapy (see "Nivolumab," "Pembrolizumab," and "Atezolizumab," pages 522, 523, and 524). ${ }^{171,175,201}$

For the 2017 update (Version 2.2017), the NCCN panel deleted the recommendation for erlotinib as subsequent therapy (and as switch maintenance therapy) for patients with nonsquamous NSCLC and PS 0 to 2 but without EGFR mutations based on results from a phase III randomized trial (IUNO) and revised indication by the FDA. The data showed that OS and PFS were not improved in patients receiving erlotinib compared with 
placebo. $^{241}$ Ramucirumab/docetaxel is an option for subsequent therapy for all histologic subtypes based on a phase III randomized trial. ${ }^{242}$ The median OS was slightly increased with ramucirumab/ docetaxel versus docetaxel alone (10.5 vs 9.1 months, respectively). Contraindications for ramucirumab/docetaxel therapy include risk for severe hemorrhage, grade 3 to 4 gastrointestinal bleeding, gastrointestinal perforation or fistula, and poorly controlled hypertension.

Docetaxel has been proven superior to best supportive care, vinorelbine, or ifosfamide with improved survival and quality of life. ${ }^{231,232}$ Compared with docetaxel, pemetrexed has similar median survival but less toxicity. ${ }^{233,243}$ Pemetrexed is recommended in patients with nonsquamous NSCLC. ${ }^{244}$ Docetaxel is recommended for patients with wildtype EGFR tumors based on 2 randomized trials comparing erlotinib versus docetaxel. ${ }^{245,246}$ In patients with PS of 3 to 4 , best supportive care is recommended (see NSCL-24, page 513 and NSCL-25, page 514). 9,247,248 Patients often have a limited response to subsequent chemotherapy other than immune checkpoint inhibitors, although it may serve a useful palliative role. ${ }^{249}$

The NCCN panel deleted erlotinib as an option for subsequent therapy for patients with squamous cell NSCLC based on a study comparing afatinib with erlotinib; this study was statistically significant but not clinically significant. ${ }^{158}$ OS was slightly better in the afatinib group than in the erlotinib group (median OS, 7.9 months [95\% CI, 7.2-8.7] vs 6.8 months [95\% CI, 5.9-7.8]; HR, 0.81 [95\% CI, 0.690.95]; $P=.0077$ ); however, almost $60 \%$ of patients in each arm had grade $\geq 3$ AEs. In contrast, the median OS was 9.2 months with nivolumab compared with
6.0 months for docetaxel for patients with squamous cell NSCLC. ${ }^{175}$ In addition, only $7 \%$ of patients receiving nivolumab had grade $\geq 3$ AEs. Erlotinib and afatinib are not recommended as second-line therapy for squamous cell carcinoma based on a phase III randomized trial showing low response rates and because they are less efficacious and safe compared with other available options. ${ }^{158}$

If patients with either ALK fusions or sensitizing EGFR mutations progress with symptomatic systemic multiple lesions after therapy with crizotinib, erlotinib, gefitinib, or afatinib and/or after ceritinib, alectinib, or osimertinib, then first-line doublet chemotherapy options are recommended for either nonsquamous NSCLC or squamous cell carcinoma. ${ }^{250}$ Erlotinib, gefitinib, or afatinib may be continued in patients with sensitizing EGFR mutations whose disease has progressed after first-line therapy. ${ }^{15,218-220}$ Osimertinib is recommended for patients with T790M whose disease becomes resistant to erlotinib, afatinib, or gefitinib. ${ }^{39}$ Afatinib/cetuximab may be considered for patients with sensitizing EGFR mutations whose disease has progressed after EGFR TKI therapy and chemotherapy. ${ }^{238}$ Ceritinib or alectinib is recommended in patients with ALKpositive NSCLC whose disease has progressed after first-line therapy with crizotinib or who are intolerant to crizotinib. ${ }^{95,98}$ Nivolumab, pembrolizumab, atezolizumab, docetaxel with or without ramucirumab (category 2B for both), gemcitabine (category 2B), or pemetrexed (nonsquamous only) (category $2 \mathrm{~B}$ ) are recommended for subsequent therapy after second disease progression in patients with advanced NSCLC and PS 0 to 2 if these agents have not already been given. $226,246,251,252$

\section{References}

1. Ettinger DS, Cox JD, Ginsberg RJ, et al. NCCN non-small-cell lung cancer practice guidelines. The National Comprehensive Cancer Network. Oncology (Williston Park) 1996;10:81-111.

2. Torre LA, Siegel RL, Jemal A. Lung cancer statistics. Adv Exp Med Biol 2016;893:1-19.

3. Siegel RL, Miller KD, Jemal A. Cancer statistics, 2017. CA Cancer J Clin 2017;67:7-30.

4. Howlader N, Noone AM, Krapcho M, et al. SEER Cancer Statistics Review, 1975-2013, based on November 2015 SEER data submission, posted to the SEER web site, April 2016. Bethesda, MD: National Cancer Institute; 2016. Available at: http://seer.cancer.gov/csr/1975_2013/. Accessed March 3, 2017.

5. Johnson DH, Schiller JH, Bunn PA Jr. Recent clinical advances in lung cancer management. J Clin Oncol 2014;32:973-982.
6. Reck M, Heigener DF, Mok T, et al. Management of non-small-cell lung cancer: recent developments. Lancet 2013;382:709-719.

7. Forde PM, Ettinger DS. Targeted therapy for non-small-cell lung cancer: past, present and future. Expert Rev Anticancer Ther 2013;13:745-758.

8. Ettinger DS. Ten years of progress in non-small cell lung cancer. J Natl Compr Canc Netw 2012;10:292-295.

9. Simoff MJ, Lally B, Slade MG, et al. Symptom management in patients with lung cancer: Diagnosis and management of lung cancer, 3rd ed: American College of Chest Physicians evidence-based clinical practice guidelines. Chest 2013;143:e455S-497S.

10. Travis WD, Brambilla E, Nicholson AG, et al. The 2015 World Health Organization Classification of Lung Tumors: impact of genetic, clinical and radiologic advances since the 2004 classification. J Thorac Oncol 2015;10:1243-1260. 
11. Travis WD, Brambilla E, Burke AP, et al. WHO Classification of Tumours of the Lung, Pleura, Thymus and Heart, Volume 7. Lyon, France: International Agency for Research on Cancer; 2015:412.

12. Spiro SG, Gould MK, Colice GL; American College of Chest Physicians. Initial evaluation of the patient with lung cancer: symptoms, signs, laboratory tests, and paraneoplastic syndromes: ACCP evidenced-based clinical practice guidelines (2nd edition). Chest 2007;132:149S-160S.

13. Silvestri GA, Gould MK, Margolis ML, et al. Noninvasive staging of nonsmall cell lung cancer: ACCP evidenced-based clinical practice guidelines (2nd edition). Chest 2007;132:178S-201S

14. De Wever W, Vankan Y, Stroobants S, Verschakelen J. Detection of extrapulmonary lesions with integrated PET/CT in the staging of lung cancer. Eur Respir J 2007;29:995-1002.

15. Langer CJ. Epidermal growth factor receptor inhibition in mutation-positive non-small-cell lung cancer: is afatinib better or simply newer? J Clin Oncol 2013;31:3303-3306.

16. Douillard JY, Ostoros G, Cobo M, et al. First-line gefitinib in Caucasian EGFR mutation-positive NSCLC patients: a phase-IV, open-label, singlearm study. Br J Cancer 2014;110:55-62.

17. Nelson V, Ziehr J, Agulnik M, Johnson M. Afatinib: emerging nextgeneration tyrosine kinase inhibitor for NSCLC. Onco Targets Ther 2013;6:135-143

18. De Greve J, Teugels E, Geers C, et al. Clinical activity of afatinib (BIBW 2992) in patients with lung adenocarcinoma with mutations in the kinase domain of HER2/neu. Lung Cancer 2012;76:123-127.

19. Dungo RT, Keating GM. Afatinib: first global approval. Drugs 2013;73:15031515

20. Sequist LV, Yang JC, Yamamoto N, et al. Phase III study of afatinib or cisplatin plus pemetrexed in patients with metastatic lung adenocarcinoma with EGFR mutations. J Clin Oncol 2013;31:3327-3334.

21. Hirsch FR, Bunn PA Jr. EGFR testing in lung cancer is ready for prime time. Lancet Oncol 2009;10:432-433.

22. Riely GJ, Politi KA, Miller VA, Pao W. Update on epidermal growth factor receptor mutations in non-small cell lung cancer. Clin Cancer Res 2006;12:7232-7241.

23. Arcila ME, Nafa K, Chaft JE, et al. EGFR exon 20 insertion mutations in lung adenocarcinomas: prevalence, molecular heterogeneity, and clinicopathologic characteristics. Mol Cancer Ther 2013;12:220-229.

24. Oxnard GR, Lo PC, Nishino $M$, et al. Natural history and molecular characteristics of lung cancers harboring EGFR exon 20 insertions. J Thorac Oncol 2013;8:179-184.

25. Lund-Iversen M, Kleinberg L, Fjellbirkeland L, et al. Clinicopathological characteristics of 11 NSCLC patients with EGFR-exon 20 mutations. J Thorac Oncol 2012;7:1471-1473.

26. Yasuda H, Kobayashi S, Costa DB. EGFR exon 20 insertion mutations in non-small-cell lung cancer: preclinical data and clinical implications. Lancet Oncol 2012;13:e23-31.

27. Riely GJ, Yu HA. EGFR: the paradigm of an oncogene-driven lung cancer Clin Cancer Res 2015;21:2221-2226.

28. Yu PP, Vose JM, Hayes DF. Genetic cancer susceptibility testing: increased technology, increased complexity. J Clin Oncol 2015;33:3533-3534.

29. Yu HA, Arcila ME, Rekhtman N, et al. Analysis of tumor specimens at the time of acquired resistance to EGFR-TKI therapy in 155 patients with EGFR-mutant lung cancers. Clin Cancer Res 2013;19:2240-2247.

30. Finlay MR, Anderton M, Ashton S, et al. Discovery of a potent and selective EGFR inhibitor (AZD9291) of both sensitizing and T790M resistance mutations that spares the wild type form of the receptor. J Med Chem 2014;57:8249-8267.

31. Gainor JF, Shaw AT. Emerging paradigms in the development of resistance to tyrosine kinase inhibitors in lung cancer. J Clin Oncol 2013;31:3987-3996.

32. Pao W, Miller VA, Politi KA, et al. Acquired resistance of lung adenocarcinomas to gefitinib or erlotinib is associated with a second mutation in the EGFR kinase domain. PLoS Med 2005;2:e73.

33. Kosaka T, Yatabe Y, Endoh H, et al. Analysis of epidermal growth factor receptor gene mutation in patients with non-small cell lung cancer an acquired resistance to gefitinib. Clin Cancer Res 2006;12:5764-5769.

34. Onitsuka $T$, Uramoto $H$, Nose $N$, et al. Acquired resistance to gefitinib: the contribution of mechanisms other than the T790M, MET, and HGF status. Lung Cancer 2010;68:198-203.

35. RosellR, Carcereny E, Gervais R, etal.Erlotinib versus standard chemotherapy as first-line treatment for European patients with advanced EGFR mutation positive non-small-cell lung cancer (EURTAC): a multicentre, open-label, randomised phase 3 trial. Lancet Oncol 2012;13:239-246.
36. Mok TS, Wu YL, Thongprasert S, et al. Gefitinib or carboplatin-paclitaxel in pulmonary adenocarcinoma. N Engl J Med 2009;361:947-957.

37. Mok TS, Wu YL, Ahn MJ, et al. Osimertinib or platinum-pemetrexed in EGFR T790M-positive lung cancer. N Engl J Med 2017;376:629-640.

38. Rosell R, Molina MA, Costa C, et al. Pretreatment EGFR T790M mutation and BRCA1 mRNA expression in erlotinib-treated advanced non-small-cell lung cancer patients with EGFR mutations. Clin Cancer Res 2011;17:11601168 .

39. Janne PA, Yang JC, Kim DW, et al. AZD9291 in EGFR inhibitor-resistant non-small-cell lung cancer. N Engl J Med 2015;372:1689-1699.

40. Sequist LV, Waltman BA, Dias-Santagata D, et al. Genotypic and histological evolution of lung cancers acquiring resistance to EGFR inhibitors. Sci Transl Med 2011;3:75ra26.

41. Oxnard GR. Strategies for overcoming acquired resistance to epidermal growth factor receptor: targeted therapies in lung cancer. Arch Pathol Lab Med 2012;136:1205-1209.

42. Suda K, Mizuuchi H, Maehara Y, Mitsudomi T. Acquired resistance mechanisms to tyrosine kinase inhibitors in lung cancer with activating epidermal growth factor receptor mutation-diversity, ductility, and destiny. Cancer Metastasis Rev 2012;31:807-814.

43. Han SW, Kim TY, Jeon YK, et al. Optimization of patient selection for gefitinib in non-small cell lung cancer by combined analysis of epidermal growth factor receptor mutation, $\mathrm{K}$-ras mutation, and Akt phosphorylation. Clin Cancer Res 2006;12:2538-2544.

44. Dacic S. EGFR assays in lung cancer. Adv Anat Pathol 2008;15:241-247.

45. Sholl LM, Xiao Y, Joshi V, et al. EGFR mutation is a better predictor of response to tyrosine kinase inhibitors in non-small cell lung carcinoma than FISH, CISH, and immunohistochemistry. Am J Clin Pathol 2010;133:922934.

46. Westwood M, Joore M, Whiting $\mathrm{P}$, et al. Epidermal growth factor receptor tyrosine kinase (EGFR-TK) mutation testing in adults with locally advanced or metastatic non-small cell lung cancer: a systematic review and costeffectiveness analysis. Health Technol Assess 2014;18:1-166.

47. Eberhard DA, Giaccone G, Johnson BE, Non-Small-Cell Lung Cancer Working Group. Biomarkers of response to epidermal growth factor receptor inhibitors in Non-Small-Cell Lung Cancer Working Group: standardization for use in the clinical trial setting. J Clin Oncol 2008;26:983-994.

48. Pao W, Ladanyi M. Epidermal growth factor receptor mutation testing in lung cancer: searching for the ideal method. Clin Cancer Res 2007;13:49544955 .

49. Shepherd FA, Tsao MS. Epidermal growth factor receptor biomarkers in non-small-cell lung cancer: a riddle, wrapped in a mystery, inside an enigma. J Clin Oncol 2010;28:903-905.

50. Dias-Santagata D, Akhavanfard S, David SS, et al. Rapid targeted mutational analysis of human tumours: a clinical platform to guide personalized cancer medicine. EMBO Mol Med 2010;2:146-158.

51. Li T, Kung HJ, Mack PC, Gandara DR. Genotyping and genomic profiling of non-small-cell lung cancer: implications for current and future therapies. J Clin Oncol 2013;31:1039-1049.

52. Miller VA, Riely GJ, Zakowski MF, et al. Molecular characteristics of bronchioloalveolar carcinoma and adenocarcinoma, bronchioloalveolar carcinoma subtype, predict response to erlotinib. J Clin Oncol 2008;26:14721478 .

53. Sequist LV, Martins RG, Spigel D, et al. First-line gefitinib in patients with advanced non-small-cell lung cancer harboring somatic EGFR mutations. J Clin Oncol 2008;26:2442-2449.

54. Paik PK, Varghese AM, Sima CS, et al. Response to erlotinib in patients with EGFR mutant advanced non-small cell lung cancers with a squamous or squamous-like component. Mol Cancer Ther 2012;11:2535-2540.

55. Mitsudomi T, Morita S, Yatabe Y, et al. Gefitinib versus cisplatin plus docetaxel in patients with non-small-cell lung cancer harbouring mutations of the epidermal growth factor receptor (WJTOG3405): an open label, randomised phase 3 trial. Lancet Oncol 2010;11:121-128.

56. Maemondo M, Inoue $A$, Kobayashi $K$, et al. Gefitinib or chemotherapy for non-small-cell lung cancer with mutated EGFR. N Engl J Med 2010;362:2380-2388.

57. Zhou C, Wu YL, Chen G, et al. Erlotinib versus chemotherapy as first-line treatment for patients with advanced EGFR mutation-positive non-smallcell lung cancer (OPTIMAL, CTONG-0802): a multicentre, open-label, randomised, phase 3 study. Lancet Oncol 2011;12:735-742.

58. Zhou C, Wu YL, Chen G, et al. Updated efficacy and quality-of-life (QoL) analyses in OPTIMAL, a phase III, randomized, open-label study of first-line erlotinib versus gemcitabine/carboplatin in patients with EGFR-activating 
mutation-positive (EGFR Act Mut+) advanced non-small cell lung cancer (NSCLC) [abstract]. J Clin Oncol 2011;29(Suppl 15):Abstract 7520.

59. Yang JC, Hirsh V, Schuler M, et al. Symptom control and quality of life in LUX-Lung 3: a phase III study of afatinib or cisplatin/pemetrexed in patients with advanced lung adenocarcinoma with EGFR mutations. J Clin Oncol 2013;31:3342-3350.

60. Yang JC, Wu YL, Schuler M, et al. Afatinib versus cisplatin-based chemotherapy for EGFR mutation-positive lung adenocarcinoma (LUXLung 3 and LUX-Lung 6): analysis of overall survival data from two randomised, phase 3 trials. Lancet Oncol 2015;16:141-151.

61. Kwak EL, Bang YJ, Camidge DR, et al. Anaplastic lymphoma kinase inhibition in non-small-cell lung cancer. N Engl J Med 2010;363:1693-1703.

62. Shaw AT, Yeap BY, Mino-Kenudson M, et al. Clinical features and outcome of patients with non-small-cell lung cancer who harbor EML4-ALK. J Clin Oncol 2009;27:4247-4253.

63. Sun JM, Lira M, Pandya K, et al. Clinical characteristics associated with ALK rearrangements in never-smokers with pulmonary adenocarcinoma. Lung Cancer 2014;83:259-264.

64. Wong DW, Leung EL, So KK, et al. The EML4-ALK fusion gene is involved in various histologic types of lung cancers from nonsmokers with wild-type EGFR and KRAS. Cancer 2009;115:1723-1733.

65. Rogers TM, Russell PA, Wright G, et al. Comparison of methods in the detection of ALK and ROS1 rearrangements in lung cancer. J Thorac Oncol 2015;10:611-618.

66. von Laffert $M$, Warth A, Penzel R, et al. Multicenter immunohistochemical ALK-testing of non-small-cell lung cancer shows high concordance after harmonization of techniques and interpretation criteria. J Thorac Oncol 2014;9:1685-1692.

67. Wynes MW, Sholl LM, Dietel M, et al. An international interpretation study using the ALK IHC antibody D5F3 and a sensitive detection kit demonstrates high concordance between ALK IHC and ALK FISH and between evaluators. J Thorac Oncol 2014;9:631-638.

68. Ali G, Proietti A, Pelliccioni S, et al. ALK rearrangement in a large series of consecutive non-small cell lung cancers: comparison between a new immunohistochemical approach and fluorescence in situ hybridization for the screening of patients eligible for crizotinib treatment. Arch Pathol Lab Med 2014;138:1449-1458.

69. Zhou J, Zhao J, Sun K, et al. Accurate and economical detection of ALK positive lung adenocarcinoma with semiquantitative immunohistochemical screening. PLoS One 2014;9:e92828.

70. Lindeman NI, Cagle PT, Beasley MB, et al. Molecular testing guideline for selection of lung cancer patients for EGFR and ALK tyrosine kinase inhibitors: guideline from the College of American Pathologists, International Association for the Study of Lung Cancer, and Association for Molecular Pathology. J Thorac Oncol 2013;8:823-859.

71. Thunnissen E, Bubendorf L, Dietel M, et al. EML4-ALK testing in nonsmall cell carcinomas of the lung: a review with recommendations. Virchows Arch 2012;461:245-257.

72. Kim H, Yoo SB, Choe JY, et al. Detection of ALK gene rearrangement in non-small cell lung cancer: a comparison of fluorescence in situ hybridization and chromogenic in situ hybridization with correlation of ALK protein expression. J Thorac Oncol 2011;6:1359-1366.

73. Rodig SJ, Mino-Kenudson M, Dacic S, et al. Unique clinicopathologic features characterize ALK-rearranged lung adenocarcinoma in the western population. Clin Cancer Res 2009;15:5216-5223.

74. Mino-Kenudson $M$, Chirieac LR, Law $K$, et al. A novel, highly sensitive antibody allows for the routine detection of ALK-rearranged lung adenocarcinomas by standard immunohistochemistry. Clin Cancer Res 2010;16:1561-1571.

75. Ali SM, Hensing T, Schrock AB, et al. Comprehensive genomic profiling identifies a subset of crizotinib-responsive ALK-rearranged non-small cell lung cancer not detected by fluorescence in situ hybridization. Oncologist 2016;21:762-770.

76. Wallander ML, Geiersbach KB, Tripp SR, Layfield LJ. Comparison of reverse transcription-polymerase chain reaction, immunohistochemistry, and fluorescence in situ hybridization methodologies for detection of echinoderm microtubule-associated proteinlike 4-anaplastic lymphoma kinase fusionpositive non-small cell lung carcinoma: implications for optimal clinical testing. Arch Pathol Lab Med 2012;136:796-803.

77. Weickhardt AJ, Aisner DL, Franklin WA, et al. Diagnostic assays for identification of anaplastic lymphoma kinase-positive non-small cell lung cancer. Cancer 2013;119:1467-1477.

78. Kazandjian D, Blumenthal GM, Chen HY, et al. FDA approval summary: crizotinib for the treatment of metastatic non-small cell lung cancer with anaplastic lymphoma kinase rearrangements. Oncologist 2014;19:e5-11.
79. Awad MM, Oxnard GR, Jackman DM, et al. MET exon 14 mutations in non-small-cell lung cancer are associated with advanced age and stagedependent MET genomic amplification and c-Met overexpression. J Clin Oncol 2016;34:721-730.

80. Mazieres J, Zalcman G, Crino L, et al. Crizotinib therapy for advanced lung adenocarcinoma and a ROS1 rearrangement: results from the EUROS1 cohort. J Clin Oncol 2015;33:992-999.

81. Solomon BJ, Mok T, Kim DW, et al. First-line crizotinib versus chemotherapy in ALK-positive lung cancer. N Engl J Med 2014;371:2167-2177.

82. Shaw AT, Kim DW, Nakagawa $K$, et al. Crizotinib versus chemotherapy in advanced ALK-positive lung cancer. N Engl J Med 2013;368:2385-2394.

83. Crino L, Kim D, Riely GJ, et al. Initial phase II results with crizotinib in advanced ALK-positive non-small cell lung cancer (NSCLC): PROFILE 1005 [abstract]. J Clin Oncol 2011;29(Suppl 15):Abstract 7514.

84. Camidge DR, Bang Y, Kwak EL, et al. Progression-free survival (PFS) from a phase I study of crizotinib (PF-02341066) in patients with ALK-positive non-small cell lung cancer (NSCLC) [abstract]. J Clin Oncol 2011;29(Suppl 15):Abstract 2501.

85. Rodig SJ, Shapiro GI. Crizotinib, a small-molecule dual inhibitor of the c-Met and ALK receptor tyrosine kinases. Curr Opin Investig Drugs 2010;11:1477-1490

86. Costa DB, Shaw AT, Ou SH, et al. Clinical experience with crizotinib in patients with advanced ALK-rearranged non-small-cell lung cancer and brain metastases. J Clin Oncol 2015;33:1881-1888.

87. Camidge DR, Bang YJ, Kwak EL, et al. Activity and safety of crizotinib in patients with ALK-positive non-small-cell lung cancer: updated results from a phase 1 study. Lancet Oncol 2012;13:1011-1019.

88. Shaw AT, Yeap BY, Solomon BJ, et al. Impact of crizotinib on survival in patients with advanced, ALK-positive NSCLC compared with historical controls [abstract]. J Clin Oncol 2011;29(Suppl 15):Abstract 7507.

89. Rothenstein JM, Letarte N. Managing treatment-related adverse events associated with Alk inhibitors. Curr Oncol 2014;21:19-26.

90. Brosnan EM, Weickhardt AJ, Lu X, et al. Drug-induced reduction in estimated glomerular filtration rate in patients with ALK-positive nonsmall cell lung cancer treated with the ALK inhibitor crizotinib. Cancer 2014;120:664-674.

91. Bang YJ. Treatment of ALK-positive non-small cell lung cancer. Arch Pathol Lab Med 2012;136:1201-1204.

92. Choi YL, Soda M, Yamashita Y, et al. EML4-ALK mutations in lung cancer that confer resistance to ALK inhibitors. N Engl J Med 2010;363:1734-1739.

93. Frampton JE. Crizotinib: a review of its use in the treatment of anaplastic lymphoma kinase-positive, advanced non-small cell lung cancer. Drugs 2013;73:2031-2051.

94. Kim DW, Tiseo M, Ahn MJ, et al. Brigatinib (BRG) in patients (pts) with crizotinib (CRZ)-refractory ALK+ non-small cell lung cancer (NSCLC) first report of efficacy and safety from a pivotal randomized phase (ph) 2 trial (ALTA) [abstract]. J Clin Oncol 2016;34(Suppl):Abstract 9007.

95. Ou SI, Ahn JS, De Petris L, et al. Alectinib in crizotinib-refractory ALKrearranged non-small-cell lung cancer: a phase II global study. J Clin Oncol 2016;34:661-668.

96. Gadgeel SM, Gandhi L, Riely GJ, et al. Safety and activity of alectinib against systemic disease and brain metastases in patients with crizotinib-resistant ALK-rearranged non-small-cell lung cancer (AF-002JG): results from the dose-finding portion of a phase 1/2 study. Lancet Oncol 2014;15:1119-1128.

97. Stinchcombe TE. Novel agents in development for advanced non-small cell lung cancer. Ther Adv Med Oncol 2014;6:240-253.

98. Shaw AT, Kim DW, Mehra R, et al. Ceritinib in ALK-rearranged non-smallcell lung cancer. N Engl J Med 2014;370:1189-1197.

99. Solomon B, Wilner KD, Shaw AT. Current status of targeted therapy for anaplastic lymphoma kinase-rearranged non-small cell lung cancer. Clin Pharmacol Ther 2014;95:15-23.

100. Savas P, Hughes B, Solomon B. Targeted therapy in lung cancer: IPASS and beyond, keeping abreast of the explosion of targeted therapies for lung cancer. J Thorac Dis 2013;5(Suppl 5):S579-592.

101. Katayama $R$, Khan TM, Benes $C$, et al. Therapeutic strategies to overcome crizotinib resistance in non-small cell lung cancers harboring the fusion oncogene EML4-ALK. Proc Natl Acad Sci U S A 2011;108:7535-7540.

102. Sequist LV, Gettinger S, Senzer NN, et al. Activity of IPI-504, a novel heatshock protein 90 inhibitor, in patients with molecularly defined non-smallcell lung cancer. J Clin Oncol 2010;28:4953-4960.

103. Zhang S, Wang F, Keats F. AP26113, a potent ALK inhibitor, overcomes mutations in EML4-ALK that confer resistance to PF-02341066 (PF1066) [abstract]. Presented at the Proceedings of the American Association for 
Cancer Research 101st Annual Meeting; April 17-21, 2010; Washington, DC. Abstract LB-298.

104. Cheng M, Ott GR. Anaplastic lymphoma kinase as a therapeutic target in anaplastic large cell lymphoma, non-small cell lung cancer and neuroblastoma. Anticancer Agents Med Chem 2010;10:236-249.

105. Khozin S, Blumenthal GM, Zhang L, et al. FDA approval: ceritinib for the treatment of metastatic anaplastic lymphoma kinase-positive non-small cell lung cancer. Clin Cancer Res 2015;21:2436-2439.

106. Shaw AT, Gandhi L, Gadgeel S, et al. Alectinib in ALK-positive, crizotinibresistant, non-small-cell lung cancer: a single-group, multicentre, phase 2 trial. Lancet Oncol 2016;17:234-242.

107. Larkins $\mathrm{E}$, Blumenthal GM, Chen $\mathrm{H}$, et al. FDA approval: alectinib for the treatment of metastatic ALK-positive non-small cell lung cancer following crizotinib. Clin Cancer Res 2016;22:5171-5176.

108. Gainor JF, Varghese AM, Ou SH, et al. ALK rearrangements are mutually exclusive with mutations in EGFR or KRAS: an analysis of 1,683 patients with non-small cell lung cancer. Clin Cancer Res 2013;19:4273-4281.

109. Takahashi $\mathrm{T}$, Sonobe $\mathrm{M}$, Kobayashi M, et al. Clinicopathologic features of non-small-cell lung cancer with EML4-ALK fusion gene. Ann Surg Oncol 2010;17:889-897.

110. Shaw AT, Forcione DG, Digumarthy SR, Iafrate AJ. Case records of the Massachusetts General Hospital. Case 21-2011. A 31-year-old man with ALK-positive adenocarcinoma of the lung. N Engl J Med 2011;365:158-167.

111. Browning ET, Weickhardt AJ, Camidge DR. Response to crizotinib rechallenge after initial progression and intervening chemotherapy in ALK lung cancer. J Thorac Oncol 2013;8:e21.

112. West $\mathrm{H}$, Oxnard GR, Doebele RC. Acquired resistance to targeted therapies in advanced non-small cell lung cancer: new strategies and new agents. Am Soc Clin Oncol Educ Book 2013:272-278.

113. Ou SH, Janne PA, Bartlett $\mathrm{CH}$, et al. Clinical benefit of continuing ALK inhibition with crizotinib beyond initial disease progression in patients with advanced ALK-positive NSCLC. Ann Oncol 2014;25:415-422.

114. Robinson DR, Wu YM, Lin SF. The protein tyrosine kinase family of the human genome. Oncogene 2000;19:5548-5557.

115. Shaw AT, Ou SH, Bang YJ, et al. Crizotinib in ROS1-rearranged non-smallcell lung cancer. N Engl J Med 2014;371:1963-1971.

116. Bergethon $\mathrm{K}$, Shaw $\mathrm{AT}$, Ou SH, et al. ROS1 rearrangements define a unique molecular class of lung cancers. J Clin Oncol 2012;30:863-870.

117. Kim HR, Lim SM, Kim HJ, et al. The frequency and impact of ROS1 rearrangement on clinical outcomes in never smokers with lung adenocarcinoma. Ann Oncol 2013;24:2364-2370.

118. Kazandjian D, Blumenthal GM, Luo L, et al. Benefit-risk summary of crizotinib for the treatment of patients with ROS1 alteration-positive, metastatic non-small cell lung cancer. Oncologist 2016;21:974-980.

119. Clave S, Gimeno J, Munoz-Marmol AM, et al. ROS1 copy number alterations are frequent in non-small cell lung cancer. Oncotarget 2016;7:8019-8028.

120. Bubendorf $\mathrm{L}$, Buttner R, Al-Dayel F, et al. Testing for ROS1 in non-small cell lung cancer: a review with recommendations. Virchows Arch 2016;469:489503.

121. Davies KD, Le AT, Theodoro MF, et al. Identifying and targeting ROS1 gene fusions in non-small cell lung cancer. Clin Cancer Res 2012;18:4570-4579.

122. Solomon BJ, Bauer TM, Felip E, et al. Safety and efficacy of lorlatinib (PF06463922) from the dose-escalation component of a study in patients with advanced ALK+ or ROS1+ non-small cell lung cancer (NSCLC) [abstract]. J Clin Oncol 2016;34(Suppl):Abstract 9009

123. Farago AF, Le LP, Zheng $Z$, et al. Durable clinical response to entrectinib in NTRK1-rearranged non-small cell lung cancer. J Thorac Oncol 2015;10:1670-1674.

124. Zou HY, Li Q, Engstrom LD, et al. PF-06463922 is a potent and selective next-generation ROS1/ALK inhibitor capable of blocking crizotinibresistant ROS1 mutations. Proc Natl Acad Sci U S A 2015;112:3493-3498.

125. Katayama R, Kobayashi Y, Friboulet L, et al. Cabozantinib overcomes crizotinib resistance in ROS1 fusion-positive cancer. Clin Cancer Res 2015;21:166-174.

126. Cardarella S, Ortiz TM, Joshi VA, et al. The introduction of systematic genomic testing for patients with non-small-cell lung cancer. J Thorac Oncol 2012;7:1767-1774.

127. Sequist LV, Heist RS, Shaw AT, et al. Implementing multiplexed genotyping of non-small-cell lung cancers into routine clinical practice. Ann Oncol 2011;22:2616-2624.

128. Eberhard DA, Johnson BE, Amler LC, et al. Mutations in the epidermal growth factor receptor and in KRAS are predictive and prognostic indicators in patients with non-small-cell lung cancer treated with chemotherapy alone and in combination with erlotinib. J Clin Oncol 2005;23:5900-5909.

129. Tsao MS, Aviel-Ronen S, Ding K, et al. Prognostic and predictive importance of $\mathrm{p} 53$ and RAS for adjuvant chemotherapy in non small-cell lung cancer. J Clin Oncol 2007;25:5240-5247.

130. Slebos RJ, Hruban RH, Dalesio O, et al. Relationship between K-ras oncogene activation and smoking in adenocarcinoma of the human lung. J Natl Cancer Inst 1991;83:1024-1027.

131. Slebos RJ, Kibbelaar RE, Dalesio $\mathrm{O}$, et al. $\mathrm{K}$-ras oncogene activation as a prognostic marker in adenocarcinoma of the lung. $\mathrm{N}$ Engl J Med 1990;323:561-565.

132. Mitsudomi T, Steinberg SM, Oie HK, et al. ras gene mutations in nonsmall cell lung cancers are associated with shortened survival irrespective of treatment intent. Cancer Res 1991;51:4999-5002.

133. Roberts PJ, Stinchcombe TE. KRAS mutation: should we test for it, and does it matter? J Clin Oncol 2013;31:1112-1121.

134. Sholl LM, Aisner DL, Varella-Garcia M, et al. Multi-institutional oncogenic driver mutation analysis in lung adenocarcinoma: the Lung Cancer Mutation Consortium experience. J Thorac Oncol 2015;10:768-777.

135. Febbo PG, Ladanyi M, Aldape KD, et al. NCCN Task Force report: evaluating the clinical utility of tumor markers in oncology. J Natl Compr Canc Netw 2011;9(Suppl 5):S1-32; quiz S33.

136. Kerr KM, Bubendorf L, Edelman MJ, et al. Second ESMO consensus conference on lung cancer: pathology and molecular biomarkers for nonsmall-cell lung cancer. Ann Oncol 2014;25:1681-1690.

137. Calles A, Liao X, Sholl LM, et al. Expression of PD-1 and its ligands, PD-L1 and PD-L2, in smokers and never smokers with KRAS-mutant lung cancer. J Thorac Oncol 2015;10:1726-1735.

138. Janne PA, Shaw AT, Pereira JR, et al. Selumetinib plus docetaxel for KRASmutant advanced non-small-cell lung cancer: a randomised, multicentre, placebo-controlled, phase 2 study. Lancet Oncol 2013;14:38-47.

139. Besse B, Adjei A, Baas P, et al. 2nd ESMO Consensus Conference on Lung Cancer: non-small-cell lung cancer first-line/second and further lines of treatment in advanced disease. Ann Oncol 2014;25:1475-1484.

140. Sandler AB, Johnson DH, Herbst RS. Anti-vascular endothelial growth factor monoclonals in non-small cell lung cancer. Clin Cancer Res 2004;10:4258s-4262s.

141. Giaccone G. Epidermal growth factor receptor inhibitors in the treatment of non-small-cell lung cancer. J Clin Oncol 2005;23:3235-3242.

142. Cohen MH, Johnson JR, Chen YF, et al. FDA drug approval summary: erlotinib (Tarceva) tablets. Oncologist 2005;10:461-466.

143. Khozin S, Blumenthal GM, Jiang X, et al. U.S. Food and Drug Administration approval summary: erlotinib for the first-line treatment of metastatic non-small cell lung cancer with epidermal growth factor receptor exon 19 deletions or exon 21 (L858R) substitution mutations. Oncologist 2014;19:774-779.

144. Sequist LV, Joshi VA, Janne PA, et al. Response to treatment and survival of patients with non-small cell lung cancer undergoing somatic EGFR mutation testing. Oncologist 2007;12:90-98.

145. Inoue $A$, Kobayashi $K$, Usui $K$, et al. First-line gefitinib for patients with advanced non-small-cell lung cancer harboring epidermal growth factor receptor mutations without indication for chemotherapy. J Clin Oncol 2009;27:1394-1400.

146. Fukuoka M, Wu YL, Thongprasert S, et al. Biomarker analyses and final overall survival results from a phase III, randomized, open-label, first-line study of gefitinib versus carboplatin/paclitaxel in clinically selected patients with advanced non-small-cell lung cancer in Asia (IPASS). J Clin Oncol 2011;29:2866-2874.

147. Kazandjian D, Blumenthal GM, Yuan W, et al. FDA approval of gefitinib for the treatment of patients with metastatic EGFR mutation-positive nonsmall cell lung cancer. Clin Cancer Res 2016;22:1307-1312.

148. Burotto M, Manasanch EE, Wilkerson J, Fojo T. Gefitinib and erlotinib in metastatic non-small cell lung cancer: a meta-analysis of toxicity and efficacy of randomized clinical trials. Oncologist 2015;20:400-410.

149. Haspinger ER, Agustoni F, Torri $\mathrm{V}$, et al. Is there evidence for different effects among EGFR-TKIs? Systematic review and meta-analysis of EGFR tyrosine kinase inhibitors (TKIs) versus chemotherapy as first-line treatment for patients harboring EGFR mutations. Crit Rev Oncol Hematol 2015;94:213227.

150. Jackman DM, Miller VA, Cioffredi LA, et al. Impact of epidermal growth factor receptor and KRAS mutations on clinical outcomes in previously untreated non-small cell lung cancer patients: results of an online tumor registry of clinical trials. Clin Cancer Res 2009;15:5267-5273. 
151. Gridelli C, Ciardiello F, Gallo C, et al. First-line erlotinib followed by secondline cisplatin-gemcitabine chemotherapy in advanced non-small-cell lung cancer: the TORCH randomized trial. J Clin Oncol 2012;30:3002-3011.

152. Keedy VL, Temin S, Somerfield MR, et al. American Society of Clinical Oncology provisional clinical opinion: epidermal growth factor receptor (EGFR) mutation testing for patients with advanced non-small-cell lung cancer considering first-line EGFR tyrosine kinase inhibitor therapy. J Clin Oncol 2011;29:2121-2127.

153. Felip E, Gridelli C, Baas P, et al. Metastatic non-small-cell lung cancer: consensus on pathology and molecular tests, first-line, second-line, and third-line therapy: 1st ESMO Consensus Conference in Lung Cancer; Lugano 2010. Ann Oncol 2011;22:1507-1519.

154. Janne PA, Wang X, Socinski MA, et al. Randomized phase II trial of erlotinib alone or with carboplatin and paclitaxel in patients who were never or light former smokers with advanced lung adenocarcinoma: CALGB 30406 trial. J Clin Oncol 2012;30:2063-2069.

155. Masters GA, Temin S, Azzoli CG, et al. Systemic therapy for stage IV nonsmall-cell lung cancer: American Society of Clinical Oncology clinical practice guideline update. J Clin Oncol 2015;33:3488-3515.

156. Urata Y, Katakami N, Morita S, et al. Randomized phase III study comparing gefitinib with erlotinib in patients with previously treated advanced lung adenocarcinoma: WJOG 5108L. J Clin Oncol 2016;34:3248-3257.

157. FDA approves afatinib for advanced lung cancer. Oncology (Williston Park) 2013;27:813-814.

158. Soria JC, Felip E, Cobo M, et al. Afatinib versus erlotinib as second-line treatment of patients with advanced squamous cell carcinoma of the lung (LUX-Lung 8): an open-label randomised controlled phase 3 trial. Lancet Oncol 2015;16:897-907.

159. Park $K$, Tan EH, O'Byrne $K$, et al. Afatinib versus gefitinib as first-line treatment of patients with EGFR mutation-positive non-small-cell lung cancer (LUX-Lung 7): a phase 2B, open-label, randomised controlled trial. Lancet Oncol 2016;17:577-589.

160. Yang JC, Ahn M, Ramalingam SS, et al. AZD9291 in pre-treated T790M positive advanced NSCLC: AURA study phase II extension cohort [abstract]. Presented at the 16th World Conference on Lung Cancer; September 6-9, 2015; Denver, CO. Abstract 943.

161. Mitsudomi T, Tsai C, Shepherd F, et al. AZD9291 in pre-treated T790M positive advanced NSCLC: AURA2 phase II study [abstract]. Presented at the 16th World Conference on Lung Cancer; September 6-9, 2015; Denver, CO. Abstract 1406.

162. Oxnard GR, Thress KS, Alden RS, et al. Association between plasma genotyping and outcomes of treatment with osimertinib (AZD9291) in advanced non-small-cell lung cancer. J Clin Oncol 2016;34:3375-3382.

163. Sacher AG, Paweletz C, Dahlberg SE, et al. Prospective validation of rapid plasma genotyping for the detection of EGFR and KRAS mutations in advanced lung cancer. JAMA Oncol 2016;2:1014-1022.

164. Hochmair MJ, Holzer S, Filipits M, et al. EGFR T790M resistance mutation in NSCLC: real-life data of patients treated with osimertinib [abstract]. J Clin Oncol 2016;34:Abstract e20572.

165. Ricciuti B, Chiari R, Chiarini P, et al. Osimertinib (AZD9291) and CNS response in two radiotherapy-naïve patients with EGFR-mutant and T790M-positive advanced non-small cell lung cancer. Clin Drug Investig 2016;36:683-686.

166. Reichegger H, Jochum W, Forbs D, et al. Rapid intracranial response to osimertinib in a patient with epidermal growth factor receptor T790Mpositive adenocarcinoma of the lung. Oncol Res Treat 2016;39:461-463.

167. Ballard P, Yates JW, Yang Z, et al. Preclinical comparison of osimertinib with other EGFR-TKIs in EGFR-mutant NSCLC brain metastases models, and early evidence of clinical brain metastases activity. Clin Cancer Res 2016;22:5130-5140.

168. Kim DW, Mehra R, Tan DS, et al. Activity and safety of ceritinib in patients with ALK-rearranged non-small-cell lung cancer (ASCEND-1): updated results from the multicentre, open-label, phase 1 trial. Lancet Oncol 2016;17:452-463.

169. Crino L, Ahn MJ, De Marinis F, et al. Multicenter phase II study of whole-body and intracranial activity with ceritinib in patients with ALKrearranged non-small-cell lung cancer previously treated with chemotherapy and crizotinib: results from ASCEND-2. J Clin Oncol 2016;34:2866-2873.

170. Soria JC, Tan DS, Chiari R, et al. First-line ceritinib versus platinumbased chemotherapy in advanced ALK-rearranged non-small-cell lung cancer (ASCEND-4): a randomised, open-label, phase 3 study. Lancet 2017;389:917-929.

171. Borghaei H, Paz-Ares L, Horn L, et al. Nivolumab versus docetaxel in advanced nonsquamous non-small-cell lung cancer. N Engl J Med 2015;373:1627-1639.
172. Ribas A. Releasing the brakes on cancer immunotherapy. N Engl J Med 2015;373:1490-1492.

173. Brahmer JR, Hammers H, Lipson EJ. Nivolumab: targeting PD-1 to bolster antitumor immunity. Future Oncol 2015;11:1307-1326.

174. Melosky B, Chu Q, Juergens $\mathrm{R}$, et al. Pointed progress in second-line advanced non-small-cell lung cancer: the rapidly evolving field of checkpoin inhibition. J Clin Oncol 2016;34:1676-1688.

175. Brahmer J, Reckamp KL, Baas $P$, et al. Nivolumab versus docetaxe in advanced squamous-cell non-small-cell lung cancer. N Engl J Med 2015;373:123-135.

176. Herbst RS, Baas P, Kim DW, et al. Pembrolizumab versus docetaxel for previously treated, PD-L1-positive, advanced non-small-cell lung cancer (KEYNOTE-010): a randomised controlled trial. Lancet 2016;387:15401550.

177. Chiou VL, Burotto M. Pseudoprogression and immune-related response in solid tumors. J Clin Oncol 2015;33:3541-3543.

178. Rittmeyer A, Barlesi F, Waterkamp D, et al. Atezolizumab versus docetaxe in patients with previously treated non-small-cell lung cancer (OAK) a phase 3, open-label, multicentre randomised controlled trial. Lancet 2017;389:255-265.

179. Garon EB, Rizvi NA, Hui R, et al. Pembrolizumab for the treatment of non small-cell lung cancer. N Engl J Med 2015;372:2018-2028.

180. Rizvi NA, Hellmann MD, Snyder A, et al. Cancer immunology. Mutational landscape determines sensitivity to PD-1 blockade in non-small cell lung cancer. Science 2015;348:124-128.

181. Le DT, Uram JN, Wang H, et al. PD-1 blockade in tumors with mismatchrepair deficiency. N Engl J Med 2015;372:2509-2520.

182. Nishino M, Giobbie-Hurder A, Hatabu H, et al. Incidence of programmed cell death 1 inhibitor-related pneumonitis in patients with advanced cancer: a systematic review and meta-analysis. JAMA Oncol 2016;2:1607-1616.

183. Naidoo J, Wang $X$, Woo KM, et al. Pneumonitis in patients treated with anti-programmed death-1/programmed death ligand 1 therapy. J Clin Onco 2017;35:709-717

184. Sgambato A, Casaluce F, Sacco PC, et al. Anti PD-1 and PDL-1 immunotherapy in the treatment of advanced non-small cell lung cancer (NSCLC): a review on toxicity profile and its management. Curr Drug Saf 2016;11:62-68.

185. Gettinger SN, Horn L, Gandhi L, et al. Overall survival and long-term safety of nivolumab (anti-programmed death 1 antibody, BMS-936558, ONO4538 ) in patients with previously treated advanced non-small-cell lung cancer. J Clin Oncol 2015;33:2004-2012.

186. Rizvi NA, Mazieres J, Planchard D, et al. Activity and safety of nivolumab, an anti-PD-1 immune checkpoint inhibitor, for patients with advanced, refractory squamous non-small-cell lung cancer (CheckMate 063): a phase 2, single-arm trial. Lancet Oncol 2015;16:257-265.

187. Postow MA, Callahan MK, Wolchok JD. Immune checkpoint blockade in cancer therapy. J Clin Oncol 2015;33:1974-1982.

188. Chapman PB, D'Angelo SP, Wolchok JD. Rapid eradication of a bulky melanoma mass with one dose of immunotherapy. N Engl J Med 2015;372:2073-2074

189. Khoja L, Butler MO, Kang SP, et al. Pembrolizumab. J Immunother Cancer 2015;3:36

190. Kazandjian D, Suzman DL, Blumenthal G, et al. FDA approval summary: nivolumab for the treatment of metastatic non-small cell lung cance with progression on or after platinum-based chemotherapy. Oncologist 2016;21:634-642

191. Phillips T, Simmons P, Inzunza HD, et al. Development of an automated PDL1 immunohistochemistry (IHC) assay for non-small cell lung cancer. App Immunohistochem Mol Morphol 2015;23:541-549.

192. Kerr KM, Tsao MS, Nicholson AG, et al. Programmed death-ligand 1 immunohistochemistry in lung cancer: in what state is this art? J Thorac Oncol 2015;10:985-989

193. Reck M, Rodriguez-Abreu D, Robinson AG, et al. Pembrolizumab versus chemotherapy for PD-L1-positive non-small-cell lung cancer. N Engl J Med 2016;375:1823-1833.

194. Gadgeel SM, Stevenson J, Langer C, et al. Pembrolizumab (pembro) plus chemotherapy as front-line therapy for advanced NSCLC: KEYNOTE-021 cohorts A-C [abstract]. J Clin Oncol 2016;34(Suppl):Abstract 9016.

195. Kerr KM, Nicolson MC. Non-small cell lung cancer, PD-L1, and the pathologist. Arch Pathol Lab Med 2016;140:249-254.

196. Kerr KM, Hirsch FR. Programmed death ligand-1 immunohistochemistry: friend or foe? Arch Pathol Lab Med 2016;140:326-331. 
197. Sul J, Blumenthal GM, Jiang $X$, et al. FDA approval summary: pembrolizumab for the treatment of patients with metastatic non-small cell lung cancer whose tumors express programmed death-ligand 1 . Oncologist 2016;21:643-650.

198. Antonia SJ, Lopez-Martin JA, Bendell J, et al. Nivolumab alone and nivolumab plus ipilimumab in recurrent small-cell lung cancer (CheckMate 032): a multicentre, open-label, phase 1/2 trial. Lancet Oncol 2016;17:883 895 .

199. Antonia SJ, Kim SW, Spira AI, et al. Safety and clinical activity of durvalumab (MEDI4736), an anti-PD-L1 antibody, in treatment-naïve patients with advanced non-small-cell lung cancer [abstract]. J Clin Oncol 2016;34(Suppl):Abstract 9029 .

200. Fehrenbacher L, Spira A, Ballinger M, et al. Atezolizumab versus docetaxe for patients with previously treated non-small-cell lung cancer (POPLAR): a multicentre, open-label, phase 2 randomised controlled trial. Lancet 2016;387:1837-1846.

201. Barlesi F, Park $K$, Ciardiello F. Primary analysis from $O A K$, a randomized phase III study comparing atezolizumab with docetaxel in 2L/3L NSCLC [abstract]. Presented at the European Society for Medical Oncology 2016 Congress (ESMO 2016); October 7-10, 2016; Copenhagen, Denmark. Abstract LBA44.

202. Scagliotti GV, Parikh P, von Pawel J, et al. Phase III study comparing cisplatin plus gemcitabine with cisplatin plus pemetrexed in chemotherapynaive patients with advanced-stage non-small-cell lung cancer. J Clin Oncol 2008;26:3543-3551.

203. Sakuma Y, Matsukuma S, Yoshihara M, et al. Distinctive evaluation of nonmucinous and mucinous subtypes of bronchioloalveolar carcinomas in EGFR and $\mathrm{K}$-ras gene-mutation analyses for Japanese lung adenocarcinomas: confirmation of the correlations with histologic subtypes and gene mutations. Am J Clin Pathol 2007;128:100-108.

204. Shaw AT, Yeap BY, Solomon BJ, et al. Effect of crizotinib on overall survival in patients with advanced non-small-cell lung cancer harbouring ALK gene rearrangement: a retrospective analysis. Lancet Oncol 2011;12:1004-1012.

205. Ou SH, Kwak EL, Siwak-Tapp C, et al. Activity of crizotinib (PF02341066), a dual mesenchymal-epithelial transition (MET) and anaplastic lymphoma kinase (ALK) inhibitor, in a non-small cell lung cancer patient with de novo MET amplification. J Thorac Oncol 2011;6:942-946.

206. Roberts PJ. Clinical use of crizotinib for the treatment of non-small cell lung cancer. Biologics 2013;7:91-101.

207. Planchard D. Identification of driver mutations in lung cancer: first step in personalized cancer. Target Oncol 2013;8:3-14.

208. Travis WD, Brambilla E, Noguchi $M$, et al. International association for the study of lung cancer/american thoracic society/european respiratory society international multidisciplinary classification of lung adenocarcinoma. J Thorac Oncol 2011;6:244-285.

209. Forbes SA, Bhamra G, Bamford S, et al. The Catalogue of Somatic Mutations in Cancer (COSMIC). Curr Protoc Hum Genet 2008;Chapter 10:Unit 1011.

210. Lee SY, Kim MJ, Jin G, et al. Somatic mutations in epidermal growth factor receptor signaling pathway genes in non-small cell lung cancers. J Thorac Oncol 2010;5:1734-1740.

211. Rekhtman N, Paik PK, Arcila ME, et al. Clarifying the spectrum of driver oncogene mutations in biomarker-verified squamous carcinoma of lung: lack of EGFR/KRAS and presence of PIK3CA/AKT1 mutations. Clin Cancer Res 2012;18:1167-1176.

212. Riely GJ, Kris MG, Zhao B, et al. Prospective assessment of discontinuation and reinitiation of erlotinib or gefitinib in patients with acquired resistance to erlotinib or gefitinib followed by the addition of everolimus. Clin Cancer Res 2007;13:5150-5155.

213. von Minckwitz G, du Bois A, Schmidt M, et al. Trastuzumab beyond progression in human epidermal growth factor receptor 2-positive advanced breast cancer: a german breast group 26/breast international group 03-05 study. J Clin Oncol 2009;27:1999-2006.

214. Simone CB 2nd, Burri SH, Heinzerling JH. Novel radiotherapy approaches for lung cancer: combining radiation therapy with targeted and immunotherapies. Transl Lung Cancer Res 2015;4:545-552.

215. Campo M, Al-Halabi $\mathrm{H}$, Khandekar M, et al. Integration of stereotactic body radiation therapy with tyrosine kinase inhibitors in stage IV oncogenedriven lung cancer. Oncologist 2016;21:964-973.

216. Iyengar P, Kavanagh BD, Wardak Z, et al. Phase II trial of stereotactic body radiation therapy combined with erlotinib for patients with limited but progressive metastatic non-small-cell lung cancer. J Clin Oncol 2014;32:3824-3830

217. Becker $\mathrm{K}, \mathrm{Xu} \mathrm{Y}$. Management of tyrosine kinase inhibitor resistance in lung cancer with EGFR mutation. World J Clin Oncol 2014;5:560-567.
218. Miller VA, Hirsh V, Cadranel J, et al. Afatinib versus placebo for patients with advanced, metastatic non-small-cell lung cancer after failure of erlotinib, gefitinib, or both, and one or two lines of chemotherapy (LUXLung 1): a phase 2b/3 randomised trial. Lancet Oncol 2012;13:528-538.

219. Katakami N, Atagi S, Goto K, et al. LUX-Lung 4: a phase II trial of afatinib in patients with advanced non-small-cell lung cancer who progressed during prior treatment with erlotinib, gefitinib, or both. J Clin Oncol 2013;31:3335-3341.

220. Hirsh V, Cadranel J, Cong XJ, et al. Symptom and quality of life benefit of afatinib in advanced non-small-cell lung cancer patients previously treated with erlotinib or gefitinib: results of a randomized phase IIb/III trial (LUXLung 1). J Thorac Oncol 2013;8:229-237.

221. Ou SH. Second-generation irreversible epidermal growth factor receptor (EGFR) tyrosine kinase inhibitors (TKIs): a better mousetrap? A review of the clinical evidence. Crit Rev Oncol Hematol 2012;83:407-421.

222. Nguyen KS, Kobayashi S, Costa DB. Acquired resistance to epidermal growth factor receptor tyrosine kinase inhibitors in non-small-cell lung cancers dependent on the epidermal growth factor receptor pathway. Clin Lung Cancer 2009;10:281-289.

223. Gazdar AF. Activating and resistance mutations of EGFR in non-small-cell lung cancer: role in clinical response to EGFR tyrosine kinase inhibitors. Oncogene 2009;28(Suppl 1)0:S24-31.

224. Chaft JE, Oxnard GR, Sima CS, et al. Disease flare after tyrosine kinase inhibitor discontinuation in patients with EGFR-mutant lung cancer and acquired resistance to erlotinib or gefitinib: implications for clinical trial design. Clin Cancer Res 2011;17:6298-6303.

225. Meoni G, Cecere FL, Lucherini E, Di Costanzo F. Medical treatment of advanced non-small cell lung cancer in elderly patients: a review of the role of chemotherapy and targeted agents. J Geriatr Oncol 2013;4:282-290.

226. Weiss JM, Stinchcombe TE. Second-line therapy for advanced NSCLC. Oncologist 2013;18:947-953.

227. van Putten JW, Baas $\mathrm{P}$, Codrington $\mathrm{H}$, et al. Activity of single-agent gemcitabine as second-line treatment after previous chemotherapy or radiotherapy in advanced non-small-cell lung cancer. Lung Cancer 2001;33:289-298.

228. Crino L, Mosconi AM, Scagliotti G, et al. Gemcitabine as second-line treatment for advanced non-small-cell lung cancer: a phase II trial. J Clin Oncol 1999;17:2081-2085.

229. Anderson H, Hopwood P, Stephens RJ, et al. Gemcitabine plus best supportive care (BSC) vs BSC in inoperable non-small cell lung cancer-a randomized trial with quality of life as the primary outcome. UK NSCLC Gemcitabine Group. Non-Small Cell Lung Cancer. Br J Cancer 2000;83:447-453.

230. Sculier JP, Lafitte JJ, Berghmans T, et al. A phase II trial testing gemcitabine as second-line chemotherapy for non small cell lung cancer. The European Lung Cancer Working Party. Lung Cancer 2000;29:67-73.

231. Fossella FV, DeVore R, Kerr RN, et al. Randomized phase III trial of docetaxel versus vinorelbine or ifosfamide in patients with advanced non-small-cell lung cancer previously treated with platinum-containing chemotherapy regimens. The TAX 320 Non-Small Cell Lung Cancer Study Group. J Clin Oncol 2000;18:2354-2362.

232. Shepherd FA, Dancey J, Ramlau R, et al. Prospective randomized trial of docetaxel versus best supportive care in patients with non-small-cell lung cancer previously treated with platinum-based chemotherapy. J Clin Oncol 2000;18:2095-2103.

233. Hanna N, Shepherd FA, Fossella FV, et al. Randomized phase III trial of pemetrexed versus docetaxel in patients with non-small-cell lung cancer previously treated with chemotherapy. J Clin Oncol 2004;22:1589-1597.

234. Shepherd FA, Rodrigues Pereira J, Ciuleanu T, et al. Erlotinib in previously treated non-small-cell lung cancer. N Engl J Med 2005;353:123-132.

235. Ades F, Yamaguchi N. WHO, RECIST, and immune-related response criteria: is it time to revisit pembrolizumab results? Ecancermedicalscience 2015;9:604.

236. Eisenhauer EA, Therasse P, Bogaerts J, et al. New response evaluation criteria in solid tumours: revised RECIST guideline (version 1.1). Eur J Cancer 2009;45:228-247.

237. Wolchok JD, Hoos A, O'Day S, et al. Guidelines for the evaluation of immune therapy activity in solid tumors: immune-related response criteria. Clin Cancer Res 2009;15:7412-7420.

238. Janjigian YY, Smit EF, Groen HJ, et al. Dual inhibition of EGFR with afatinib and cetuximab in kinase inhibitor-resistant EGFR-mutant lung cancer with and without T790M mutations. Cancer Discov 2014;4:1036-1045.

239. Gainor JF, Shaw AT, Sequist LV, et al. EGFR mutations and ALK rearrangements are associated with low response rates to PD-1 pathway 
blockade in non-small cell lung cancer: a retrospective analysis. Clin Cancer Res 2016;22:4585-4593.

240. Sacher AG, Janne PA, Oxnard GR. Management of acquired resistance to epidermal growth factor receptor kinase inhibitors in patients with advanced non-small cell lung cancer. Cancer 2014;120:2289-2298.

241. Cicenas S, Geater SL, Petrov P, et al. Maintenance erlotinib versus erlotinib at disease progression in patients with advanced non-small-cell lung cancer who have not progressed following platinum-based chemotherapy (IUNO study). Lung Cancer 2016;102:30-37.

242. Garon EB, Ciuleanu TE, Arrieta $O$, et al. Ramucirumab plus docetaxel versus placebo plus docetaxel for second-line treatment of stage IV nonsmall-cell lung cancer after disease progression on platinum-based therapy (REVEL): a multicentre, double-blind, randomised phase 3 trial. Lancet 2014;384:665-673.

243. Demarinis F, Paul S, Hanna N, et al. Survival update for the phase III study of pemetrexed vs docetaxel in non-small cell lung cancer (NSCLC) [abstract]. J Clin Oncol 2006;24(Suppl 18):Abstract 7133.

244. Ciuleanu T, Brodowicz T, Zielinski C, et al. Maintenance pemetrexed plus best supportive care versus placebo plus best supportive care for nonsmall-cell lung cancer: a randomised, double-blind, phase 3 study. Lancet 2009;374:1432-1440.

245. Garassino MC, Martelli $O$, Broggini $M$, et al. Erlotinib versus docetaxel as second-line treatment of patients with advanced non-small-cell lung cancer and wild-type EGFR tumours (TAILOR): a randomised controlled trial. Lancet Oncol 2013;14:981-988.
246. Kawaguchi T, Ando M, Asami K, et al. Randomized phase III trial of erlotinib versus docetaxel as second- or third-line therapy in patients with advanced non-small-cell lung cancer: Docetaxel and Erlotinib Lung Cancer Trial (DELTA). J Clin Oncol 2014;32:1902-1908.

247. Yates P, Schofield P, Zhao I, Currow D. Supportive and palliative care for lung cancer patients. J Thorac Dis 2013;5(Suppl 5):S623-628.

248. Ford DW, Koch KA, Ray DE, Selecky PA. Palliative and end-of-life care in lung cancer: diagnosis and management of lung cancer, 3rd ed: American College of Chest Physicians evidence-based clinical practice guidelines. Chest 2013;143:e498S-512S.

249. Eccles BK, Geldart TR, Laurence VM, et al. Experience of first- and subsequent-line systemic therapy in the treatment of non-small cell lung cancer. Ther Adv Med Oncol 2011;3:163-170.

250. Sandler A, Gray R, Perry MC, et al. Paclitaxel-carboplatin alone or with bevacizumab for non-small-cell lung cancer. N Engl J Med 2006;355:25422550 .

251. Langer CJ, Mok T, Postmus PE. Targeted agents in the third-/fourth-line treatment of patients with advanced (stage III/IV) non-small cell lung cancer (NSCLC). Cancer Treat Rev 2013;39:252-260.

252. Noble J, Ellis PM, Mackay JA, et al. Second-line or subsequent systemic therapy for recurrent or progressive non-small cell lung cancer: a systematic review and practice guideline. J Thorac Oncol 2006;1:1042-1058. 
Non-Small Cell Lung Cancer, Version 5.2017

Individual Disclosures for the Non-Small Cell Lung Cancer Panel

\begin{tabular}{|c|c|c|c|c|}
\hline Panel Member & $\begin{array}{l}\text { Clinical Research Support/Data } \\
\text { Safety Monitoring Board }\end{array}$ & $\begin{array}{l}\text { Scientific Advisory Boards, } \\
\text { Consultant, or Expert Witness }\end{array}$ & $\begin{array}{l}\text { Promotional } \\
\text { Advisory Boards, } \\
\text { Consultant, or } \\
\text { Speakers Bureau }\end{array}$ & $\begin{array}{l}\text { Date } \\
\text { Completed }\end{array}$ \\
\hline Dara L. Aisner, MD, PhD & None & None & $\begin{array}{l}\text { AstraZeneca } \\
\text { Pharmaceuticals LP; and } \\
\text { Invitae Corporation }\end{array}$ & $2 / 3 / 17$ \\
\hline Wallace Akerley, MD & $\begin{array}{l}\text { Bristol-Myers Squibb Company; Flat Iron } \\
\text { Healthcare; Genentech, Inc.; Mirati Therapeutics, } \\
\text { Inc.; and Novartis Pharmaceuticals Corporation }\end{array}$ & AstraZeneca Pharmaceuticals LP & None & $3 / 9 / 17$ \\
\hline Jessica Bauman, MD & None & None & None & $12 / 28 / 16$ \\
\hline Lucian R. Chirieac, MD & None & $\begin{array}{l}\text { Medical Science Afiliates; Shook, } \\
\text { Hardy \& Bacon; and Wilcox and Savage }\end{array}$ & None & $10 / 17 / 16$ \\
\hline Thomas A. D'Amico, MD & None & Scanlan & None & $3 / 19 / 17$ \\
\hline Malcolm M. DeCamp, MD & PulmonX & $\begin{array}{l}\text { Auris Surgical Robotics Inc.; Holaira Inc; } \\
\text { Intuitive Surgical, Inc.; and Soffio } \\
\text { Medical Inc. }\end{array}$ & None & 2/15/17 \\
\hline Thomas J. Dilling, MD, MS & None & None & None & $3 / 2 / 17$ \\
\hline Michael Dobelbower, MD, PhD & Covidien AG; and Varian Medical Systems, Inc. & None & None & $3 / 22 / 17$ \\
\hline Robert C. Doebele, MD, PhD & $\begin{array}{l}\text { ARIAD Pharmaceuticals, Inc.; AstraZeneca } \\
\text { Pharmaceuticals LP; Bristol-Myers Squibb } \\
\text { Company; GlaxoSmithKline; OncoMed } \\
\text { Pharmaceuticals; Corvus; CytRx; Ignyta; } \\
\text { Loxo Oncology; Strategia; and } \\
\text { Threshold Pharmaceuticals }\end{array}$ & None & $\begin{array}{l}\text { ARIAD Pharmaceuticals, } \\
\text { Inc.; AstraZeneca } \\
\text { Pharmaceuticals LP; } \\
\text { Trovagene; and Pfizer } \\
\text { Inc. }\end{array}$ & $10 / 28 / 16$ \\
\hline David S. Ettinger, MD & Golden Biotechnology Corp & $\begin{array}{l}\text { ARIAD Pharmaceuticals, Inc.; } \\
\text { BeyondSpring Pharmaceuticals; } \\
\text { Boehringer Ingelheim GmbH; Bristol- } \\
\text { Myers Squibb Company; Eli Lilly and } \\
\text { Company; EMD Serono; Genentech, } \\
\text { Inc.; Helsinn Therapeutics (US), Inc.; } \\
\text { Heron Therapeutics; McGivney Global } \\
\text { Consultant; and Trovagene, Inc. }\end{array}$ & None & $2 / 23 / 17$ \\
\hline Ramaswamy Govindan, MD & $\begin{array}{l}\text { Abbott Laboratories; Abraxis Oncology; ARIAD } \\
\text { Pharmaceuticals, Inc.; AstraZeneca Pharmaceuticals } \\
\text { LP; Bayer HealthCare; Boehringer Ingelheim } \\
\text { GmbH; Bristol-Myers Squibb Company; Genentech, } \\
\text { Inc.; and GlaxoSmithKline }\end{array}$ & $\begin{array}{l}\text { Abbott Laboratories; Bayer HealthCare; } \\
\text { Celgene Corporation; Clovis; Helsinn } \\
\text { Healthcare; and Roche Laboratories, Inc. }\end{array}$ & None & 2/13/17 \\
\hline Matthew A. Gubens, MD, MS & $\begin{array}{l}\text { Celgene Corporation; Merck \& Co., Inc.; } \\
\text { Novartis Pharmaceuticals Corporation; } \\
\text { OncoMed Pharmaceuticals; and Roche } \\
\text { Laboratories, Inc. }\end{array}$ & $\begin{array}{l}\text { AbbVie; ARIAD Pharmaceuticals, Inc.; } \\
\text { AstraZeneca Pharmaceuticals LP; Bristol- } \\
\text { Myers Squibb Company; Genentech, Inc.; } \\
\text { and Pfizer Inc. }\end{array}$ & None & $2 / 10 / 17$ \\
\hline Mark Hennon, MD & None & None & None & $3 / 15 / 17$ \\
\hline Leora Horn, MD, MSc, FRCPC & $\begin{array}{l}\text { AstraZeneca Pharmaceuticals LP; Bayer } \\
\text { HealthCare; Bristol-Myers Squibb Company; } \\
\text { Celgene Corporation; Eli Lilly and Company; } \\
\text { Genentech, Inc.; Merck \& Co., Inc.; Merrimack; } \\
\text { Novartis Pharmaceuticals Corporation; } \\
\text { OSI Pharmaceuticals, Inc.; and } \\
\text { Xcovery }\end{array}$ & $\begin{array}{l}\text { Bayer HealthCare; Bristol-Myers Squibb } \\
\text { Company; Eli Lilly and Company; } \\
\text { EMD Serono; Genentech, Inc.; } \\
\text { Merck \& Co., Inc.; and Xcovery }\end{array}$ & Abbvie & $10 / 10 / 16$ \\
\hline Ritsuko Komaki, MD & ACRIN & None & None & $2 / 2 / 17$ \\
\hline Rudy P. Lackner, MD & None & None & None & $2 / 24 / 17$ \\
\hline Michael Lanuti, MD & $\mathrm{NCl}$ & None & None & $1 / 25 / 17$ \\
\hline Ticiana A. Leal, MD & None & $\begin{array}{l}\text { ARIAD Pharmaceuticals, Inc.; and } \\
\text { Genentech, Inc. }\end{array}$ & None & $2 / 1 / 17$ \\
\hline Leah J. Leisch, MD & None & None & None & $1 / 23 / 17$ \\
\hline Rogerio Lilenbaum, MD & None & Genentech, Inc. & $\begin{array}{l}\text { AstraZeneca } \\
\text { Pharmaceuticals LP }\end{array}$ & $3 / 20 / 17$ \\
\hline Jules Lin, MD & None & None & Intuitive Surgical, Inc. & $1 / 23 / 17$ \\
\hline Billy W. Loo Jr, MD, PhDa & None & None & None & $10 / 13 / 16$ \\
\hline Renato Martins, MD, MPH & $\begin{array}{l}\text { AstraZeneca Pharmaceuticals LP; Bristol-Myers } \\
\text { Squibb Company; Celgene Corporation; Eisai } \\
\text { Inc.; Eli Lilly and Company; Genentech, Inc.; } \\
\text { GlaxoSmithKline; Merck \& Co., Inc.; Millennium } \\
\text { Pharmaceuticals, Inc.; Mirati Therapeutics; Novartis } \\
\text { Pharmaceuticals Corporation; and Pfizer Inc. }\end{array}$ & None & None & $2 / 21 / 17$ \\
\hline Gregory A. Otterson, MD & $\begin{array}{l}\text { Boehringer Ingelheim GmbH; Boston Biomedical; } \\
\text { Bristol-Myers Squibb Company; Celgene } \\
\text { Corporation; Clovis; Genentech, Inc.; } \\
\text { Merck \& Co., Inc.; and Pfizer Inc. }\end{array}$ & $\begin{array}{l}\text { Boehringer Ingelheim } \mathrm{GmbH} \text {; } \\
\text { Genentech, Inc.; and Novartis } \\
\text { Pharmaceuticals Corporation }\end{array}$ & None & $3 / 19 / 17$ \\
\hline Karen Reckamp, MD, MS & $\begin{array}{l}\text { Abbott Laboratories; Adaptimmune; ARIAD } \\
\text { Pharmaceuticals, Inc.; Boehringer Ingelheim } \\
\text { GmbH; Bristol-Myers Squibb Company; Clovis; } \\
\text { Eisai Inc.; Genentech, Inc.; Pfizer Inc.; and Xcovery }\end{array}$ & $\begin{array}{l}\text { Amgen Inc.; ARIAD Pharmaceuticals, Inc.; } \\
\text { Astellas; and Celgene Corporation }\end{array}$ & None & $1 / 21 / 17$ \\
\hline Gregory J. Riely, MD, PhD & $\begin{array}{l}\text { ARIAD Pharmaceuticals, Inc.; GlaxoSmithKline; } \\
\text { Infinity Pharmaceuticals; Millennium } \\
\text { Pharmaceuticals, Inc.; Novartis Pharmaceuticals } \\
\text { Corporation; Pfizer Inc.; and Roche Laboratories, } \\
\text { Inc. }\end{array}$ & Genentech, Inc. & None & $10 / 13 / 16$ \\
\hline Steven E. Schild, MD & None & None & None & $3 / 7 / 17$ \\
\hline Theresa A. Shapiro, MD, PhD & None & None & None & $3 / 8 / 17$ \\
\hline James Stevenson, MD & $\begin{array}{l}\text { Bayer HealthCare; Bristol-Myers Squibb Company; } \\
\text { and Merck \& Co., Inc. }\end{array}$ & None & None & $3 / 3 / 17$ \\
\hline Scott J. Swanson, MD & None & Covidien AG; and Ethicon, Inc. & None & $2 / 2 / 17$ \\
\hline Kurt Tauer, MD & None & None & None & $3 / 20 / 17$ \\
\hline Douglas E. Wood, MD, FRCSEd & Spiration & $\begin{array}{l}\text { GRAIL, Inc.; Lung Cancer Alliance; } \\
\text { and Spiration, Inc. }\end{array}$ & None & $1 / 6 / 17$ \\
\hline Stephen C. Yang, MD & None & None & None & $3 / 26 / 17$ \\
\hline
\end{tabular}

The NCCN Guidelines Staff have no conflicts to disclose.

aThe following individuals have disclosed that they have an Employment/ Governing Board, Patent, Equity, or Royalty conflict: Robert C. Doebele, MD, PhD: Abbott Molecular

Billy W. Loo Jr, MD, PhD: Stanford University, and TibaRay, Inc. 